OPEN ACCESS

Edited by: Nicola Silvestris,

University of Bari Aldo Moro, Italy

Reviewed by:

Abdelbaset Mohamed Elasbali,

Al Jouf University, Saudi Arabia

Luca Falzone,

Istituto Nazionale Tumori Fondazione

G. Pascale (IRCCS), Italy

${ }^{*}$ Correspondence:

Fatih M. Uckun

fatih.uckun@reven.com

Specialty section:

This article was submitted to

Cancer Epidemiology and Prevention,

a section of the journal

Frontiers in Oncology

Received: 15 August 2021

Accepted: 18 October 2021

Published: 04 November 2021

Citation:

Guven DC, Sahin TK, Kilickap S and Uckun FM (2021) Antibody Responses

to COVID-19 Vaccination in

Cancer: A Systematic Review.

Front. Oncol. 11:759108.

doi: 10.3389/fonc.2021.759108

\section{Antibody Responses to COVID-19 Vaccination in Cancer: A Systematic Review}

\author{
Deniz C. Guven ${ }^{1}$, Taha K. Sahin ${ }^{2}$, Saadettin Kilickap ${ }^{1,3}$ and Fatih M. Uckun ${ }^{4,5 *}$ \\ ${ }^{1}$ Department of Medical Oncology, Hacettepe University Cancer Institute, Ankara, Turkey, ${ }^{2}$ Department of Internal Medicine, \\ Hacettepe University Faculty of Medicine, Ankara, Turkey, ${ }^{3}$ Department of Medical Oncology, Istinye University, \\ Istanbul, Turkey, ${ }^{4}$ Department of Immunology and Inflammatory Disorders, Reven Pharmaceuticals, Westminster,

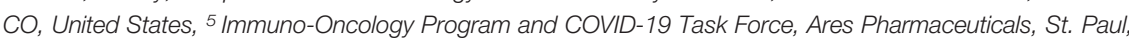 \\ MN, United States
}

Introduction: After the results of phase III vaccine studies became available, the leading oncology societies recommended two doses of COVID-19 vaccination to all patients with cancer with no specific recommendation for tumor type and active treatments. However, the data on the COVID-19 vaccine efficacy in cancer patients is limited due to exclusion of cancer patients from most vaccine clinical trials. Therefore, we systemically reviewed the available evidence evaluating the antibody responses in cancer patients.

Methods: We conducted a systematic search from the Pubmed database and calculated risk differences $(\mathrm{RD})$ and 95\% confidence intervals $(\mathrm{Cl})$ to compare seroconversion rates between cancer patients and controls using the Review Manager software, version 5.3.

Results: Our systematic search retrieved a total 27 studies and we included 17 studies with control arms in the analyses. Cancer patients had significantly lower seroconversion rates (37.3\%) than controls (74.1\%) (RD: $-0.44,95 \% \mathrm{Cl}:-0.52,-0.35, p<0.001)$ with first vaccine dose. After two doses, the seroconversion rates were $99.6 \%$ in control arm and $78.3 \%$ in cancer patients (RD: $-0.19,95 \% \mathrm{Cl}:-0.28,-0.10, \mathrm{p}<0.001)$. The difference in seroconversion rates was more pronounced patients with hematologic malignancies (72.6\%) (RD: $-0.25,95 \% \mathrm{Cl}:-0.27,-0.22, \mathrm{p}<0.001)$ than patients with solid tumors (91.6\%) (RD: $-0.09,95 \% \mathrm{Cl}:-0.13,-0.04, \mathrm{p}<0.003)$ and patients in remission (RD: -0.10 , 95\% Cl: $-0.14,-0.06, p<0.001)$.

Conclusion: In conclusion, COVID-19 vaccine seroconversion rates were significantly lower in patients with hematological malignancies and patients under active treatment. Further research focusing on the approaches to improve vaccine efficacy and exploration of novel treatment options is urgently needed for these patients.

Keywords: COVID-19, vaccination, seroconversion, cancer, antibody 


\section{INTRODUCTION}

The COVID-19 pandemic stormed the World in the last two years and caused more than four million deaths (1). Patients with cancer are among the most susceptible populations for high morbidity and mortality with COVID-19 disease (2). The increased mortality risk was especially prominent in patients with hematologic cancers, patients under active chemotherapy, and advanced age patients with additional comorbidities (3-5). The elements of the adaptive immune system, including B-cells, CD4+ T cells (especially T helper cells) and CD8+ T cells, play pivotal roles for the course, severity and health outcomes in patients with COVID-19 (6) and perturbations of the adaptive immunity have been implicated for the adverse outcomes in cancer patients with COVID-19 (7-10).

The protection of patients with cancer from COVID-19 disease while continuing optimal cancer care has been an ongoing challenge during the pandemic (11). Hopefully, the vaccination against SARS-CoV-2 showed the light at the end of the tunnel. Several vaccines, including the Pfizer/BioNTech (BNT162b2) and Moderna (mRNA-1273), exhibited safety and efficacy in large phase II and III clinical trials and received emergency approval by regulatory agencies (12-14). Almost all vaccines generated more than $90 \%$ antibody response rates and over $80 \%$ prevention rates from severe COVID-19 infection (12-14). These studies provided the foundation of a worldwide mass vaccination campaign, and to date, more than four billion doses of COVID-19 vaccines have been administered $(15,16)$ (Figure 1).
Higher case fatality rates and increased morbidity in cancer patients prompted the leading oncology groups to recommend that cancer patients should receive full COVID-19 vaccination with two doses where applicable $(17,18)$. However, the data on the vaccine efficacy is limited due to exclusion of cancer patients from most COVID-19 vaccine clinical trials (19). Both cancer and anticancer treatments challenge the proper functioning of adaptive immune machinery and could complicate the efficacy of vaccines (20). The previous experience with the influenza vaccination (21) and early reports with SARS-COV-2 vaccines (22) pointed out a decreased vaccine efficacy in patients with cancer due to both cancer and treatment-induced immunosuppression albeit with heterogeneous study populations and limited sample sizes. From these points, we systemically reviewed the available evidence of antibody responses and affecting factors for cancer patients following COVID-19 vaccination.

\section{METHODS}

\section{Literature Search}

We conducted a systematic review from the Pubmed database per the Preferred Reporting Items for Systematic Reviews and Metaanalysis guidance (23). The MeSH search terms were "vaccine" OR "vaccination" AND "cancer" OR "malignancy" OR "lymphoma" OR "leukemia" OR "myeloma". The search was limited to studies published between April 1st 2021 and July 26th 2021. We included the original research evaluating the seroconversion rates with

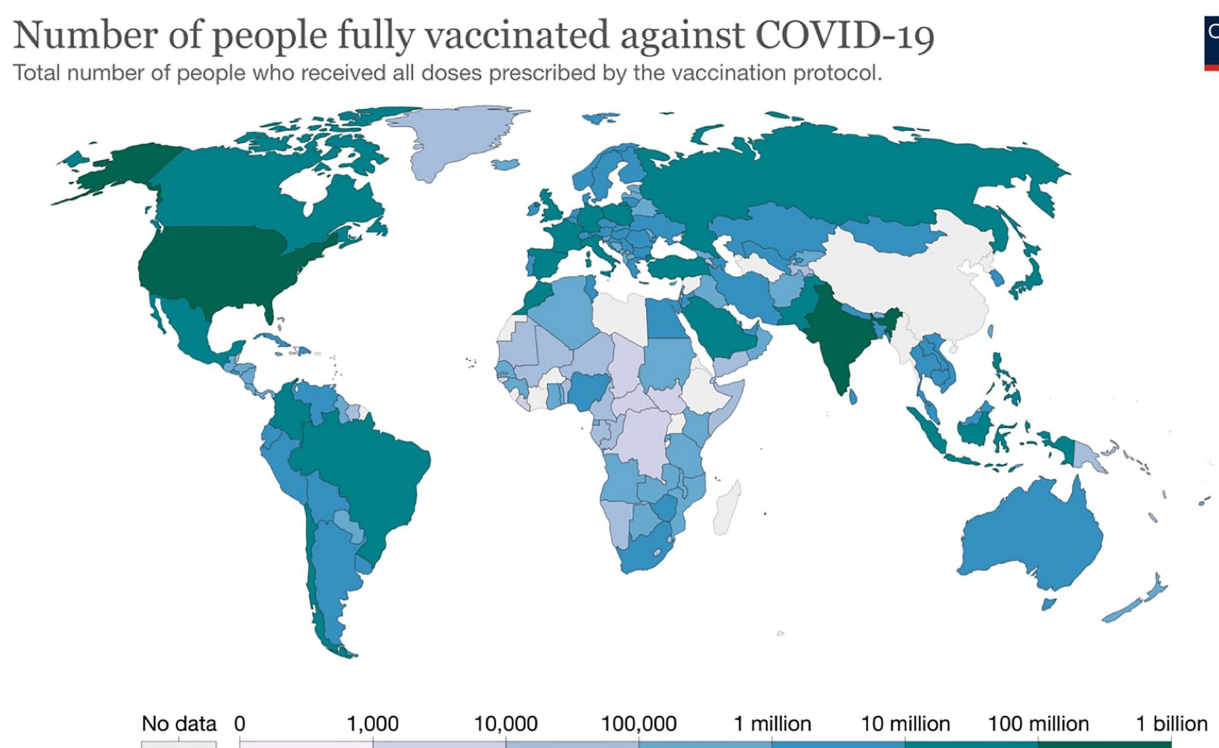

Source: Official data collated by Our World in Data - Last updated 11 August 2021, 13:00 (London time)

Note: This data is only available for countries which report the breakdown of doses administered by first and second doses. Alternative definitions of a full vaccination, e.g. having been infected with SARS-CoV-2 and having 1 dose of a 2-dose protocol, are ignored to maximize comparability between countries.

OurWorldlnData.org/coronavirus · CC BY

FIGURE 1 | Distribution of the total number of people that have been fully vaccinated against COVID-19. 
SARS-COV-2 vaccines in patients with cancer and excluded reviews, opinion papers, and commentaries.

\section{Study Selection and Data Extraction}

Our systematic search retrieved a total of 2243 records. After removing duplications $(n=692)$, we screened the remaining 1551 articles. We excluded the 1505 records due to irrelevance $(n=1111)$, reviews, commentaries, and meta-analyses $(n=369)$, articles not in the English language $(n=17)$, animal studies $(n=6)$, and retracted articles $(n=2)$. We further evaluated the remaining 46 articles and excluded 20 more records with absent details on seroconversion rates following COVID-19 vaccination in patients with cancer $(n=18)$ and studies including pediatric patients $(n=2)$ and included 26 records in review. One additional study was added to review from the reference lists of included studies making a total of 27 studies included in the systematic review. 17 studies with control arms were included in the quantitative synthesis (Figure 2).

\section{Meta-Analysis}

We conducted separate meta-analyses to compare seroconversion rates in cancer patients and healthy controls vaccinated with one or two vaccine doses. Additionally, we conducted subgroup analyses for the malignancy type (hematologic vs. non-hematologic) and status of therapy (ongoing active treatment $v s$. remission off therapy). Two authors (DCG and TKS) independently reviewed and extracted the available data for the meta-analyses, and any disagreements were resolved by the senior authors (SK, FMU). We included the studies reporting seroconversion rates in the metaanalyses, while the studies with missing data for these outcomes and studies using different outcomes (i.e., antibody titers only) were excluded from the meta-analyses.

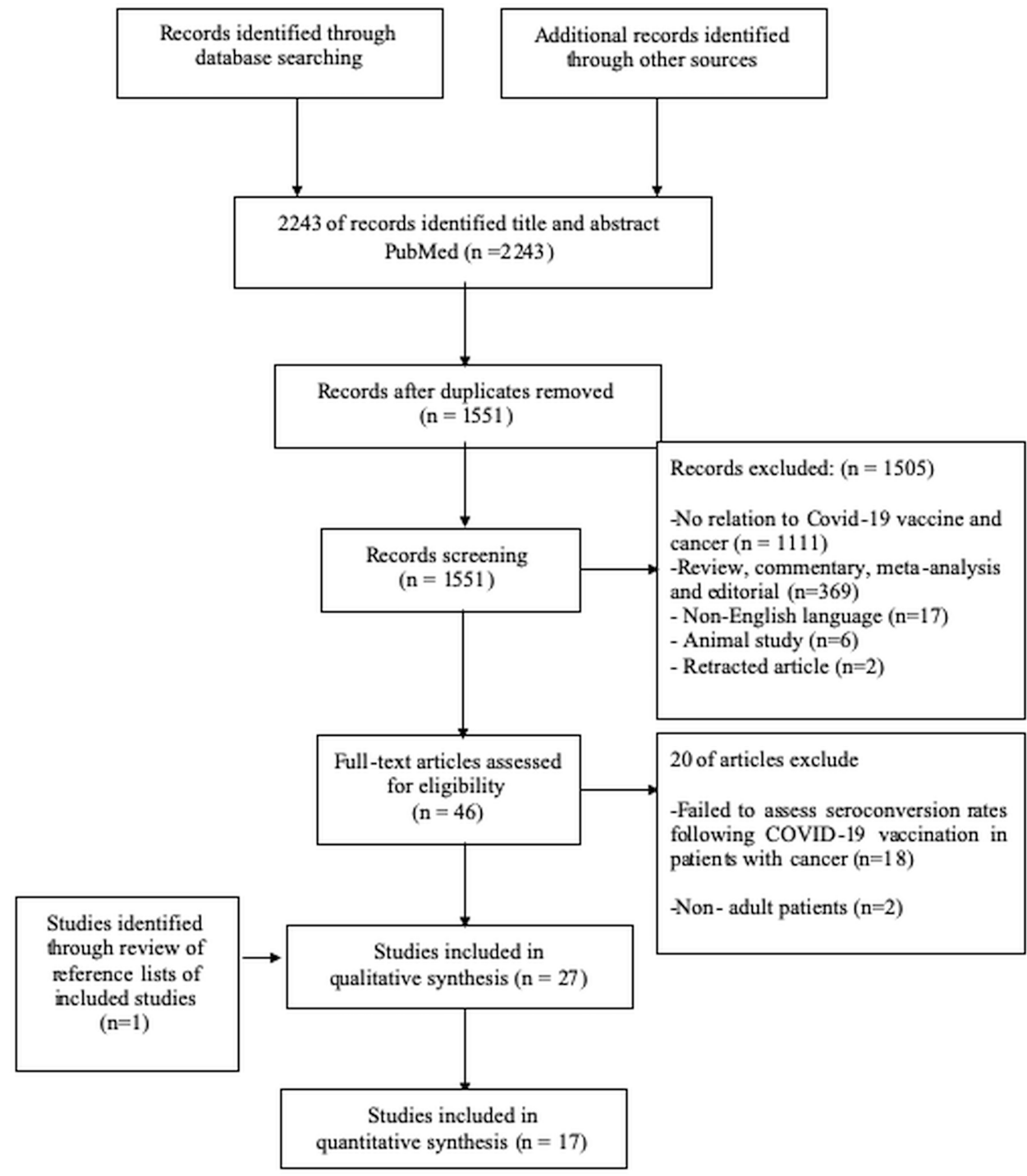

FIGURE 2 | PRISMA flow diagram. 
We recorded lead author names, journals, the total number of patients, seroconversion rates after one or two vaccines for each study. The risk of bias and individual study qualities was assessed independently by the DCG and TKS with Newcastle-Ottawa Scale (NOS) (Table 1). We performed the meta-analysis using the generic inverse-variance method with a random-effects model considering the significant heterogeneity between the studies. We selected principal summary measure as the risk differences with 95\% two-sided confidence intervals to better delineate the seronegativity risk for individual patients and to prevent overestimation of seronegativity risk in cancer patients due to almost $100 \%$ seropositivity with vaccines in healthy controls. All analyses were done using the Review Manager software, version 5.3 (The Nordic Cochrane Center, The Cochrane Collaboration, Copenhagen, Denmark). The heterogeneity within each subgroup is reported using the I-square statistics. The $\mathrm{p}$ values below 0.05 were considered statistically significant.

\section{RESULTS}

\section{Study Characteristics}

A total of 27 studies evaluated the seroconversion rates after at least one dose of a COVID-19 vaccine. The sample sizes were very variable (minimum 16- maximum 423). Most studies (18/27) included a control group which involved mostly health care workers. Seven studies included only patients with solid tumors $(22,25,27,32,34,36,39)$, four studies included both solid tumor patients and patients with hematologic malignancies $(28,33,40,41)$ and 16 studies included only patients with hematologic malignancies $(24,26,29-31,35,37,38,42-49)$. Nine studies included both patients in remission and patients under active treatment. Twelve studies measured baseline anti-SARS-CoV-2 antibodies and excluded patients with positive baseline antibody titers (27-30, 33, 37-39, 41, 44, 48, 49).Eight studies used only previous COVID-19 history as the exclusion criteria $(24,25,31,34-$
$36,43,46)$ and 4 studies included patients with previous COVID-19 history $(22,26,40,42)$. The antibody measurement methods were very heterogenous between the studies and immunoglobulin $G$ (IgG) antibodies against the SARS-CoV-2 spike protein were the most commonly used antibody assay (Table 2).

\section{Seroconversion Rates After First Vaccination}

Seroconversion rates after the first dose of vaccination and second dose of vaccination were reported in 17 studies each. Seven studies reported seroconversion rates after both the first and second vaccine doses $(27-29,32-34,41)$. Low seroconversion rates after the first vaccine dose were consistent across all studies, and the reported seroconversion rates were only around $20-30 \%$ for patients with lymphoid malignancies (Table 2). After the first vaccine dose, the seroconversion rates were quite variable in patients with solid tumors and ranged between $29 \%$ to $83 \%$. After the first dose of vaccination, the seroconversion rates of control groups were over $90 \%$ in all but 4 studies. The 4 studies with lower seroconversion rates in the control group after the first vaccine dose used mostly octogenerians as control group $(29,36,38)$. In the pooled data from 9 studies with control arms, the possibility of seroconversion was significantly lower in cancer patients $(268 / 719,37.3 \%)$ than healthy controls $(890 / 1201,74.1 \%)$ after first dose of vaccination (RD: $-0.44 \%, 95 \%$ CI: $-0.52 \%,-0.35 \%, p<0.001$ ) (Figure 3). Significant variability existed among the studies $\left(\mathrm{I}^{2}=75 \%\right)$ (Figure 3). Six studies included only patients vaccinated with the BNT162b2 vaccine, while two studies included both the BNT162b2 or AZD1222 vaccines $(35,37)$ and one study included patients vaccinated with either of the mRNA vaccines (BNT162b2 and mRNA-1273) and AZD1222 vaccine (36). Further analyses with the exclusion of studies including vaccines other mRNA vaccines (seven studies), demonstrated a consistent risk of seronegativity in cancer patients compared to controls (RD: $-0.45 \%, 95 \% \mathrm{CI}$ : $-0.58 \%,-0.33 \%, \mathrm{p}<0.001$ ) (Supplement). Similarly, in the pooled analyses of three studies (35-37) including both mRNA and

TABLE 1 | Newcastle-ottowa scores of included studies.

\begin{tabular}{|c|c|c|c|c|}
\hline Author, year & Selection & Comparability & Exposure/Outcome & Reference \\
\hline Herishanu Y, Blood & 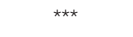 & $\star \star *$ & 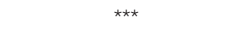 & $(24)$ \\
\hline Massarweh A, JAMA Oncol & 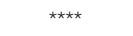 & $\star \star$ & 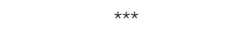 & (25) \\
\hline Palich R, Ann Onc & 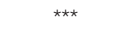 & $\star \star *$ & 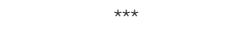 & $(22)$ \\
\hline Oekelen OV, Cancer Cell & $\star \star$ & $\star \star$ & ** & (26) \\
\hline Barrière J, Ann Onc & $\star *$ & $\star \star$ & $\star \star$ & $(27)$ \\
\hline Monin L, Lancet Oncol & 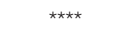 & $\star \star$ & $\star \star \star \star ~$ & (28) \\
\hline Pimpinell F, J Hematol Oncol & 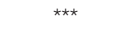 & $\star \star *$ & ** & (29) \\
\hline Avivi I, Br J Haematol & 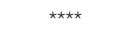 & $\star \star$ & 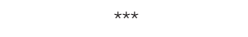 & (30) \\
\hline Tzarfati KH, Am J Hematol & 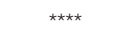 & $\star \star$ & $\star \star \star ~$ & (31) \\
\hline Shroff RT, MedRxiv & 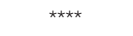 & $\star \star$ & 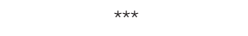 & (32) \\
\hline Addeo A, Cancer Cell & 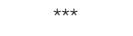 & * & ** & (33) \\
\hline Goshen-Lago T, Jama Oncol & 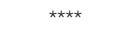 & $\star \star$ & $\star \star \star \star ~$ & (34) \\
\hline Palich R, Ann Onc 2 & 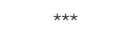 & $\star \star$ & $\star \star$ & $(22)$ \\
\hline Gavriatopoulou M, Clin Exp Med & 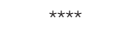 & $\star \star$ & $\star \star \star \star ~$ & (35) \\
\hline Terpos E, Journal of Hematology \& Oncology & 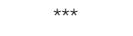 & $\star \star *$ & ** & $(36)$ \\
\hline Chowdhury $\mathrm{O}, \mathrm{Br} \mathrm{J}$ Haematol & $\star \star$ & $\star \star$ & $\star \star \star \star ~$ & (37) \\
\hline Terpos E, Blood & $\star \star \star$ & $\star \star$ & $\star \star \star \star$ & (38) \\
\hline
\end{tabular}

The stars refer to the scores. 
TABLE 2 | Summary of studies evaluating antibody responses to SARS-CoV-2 vaccination

\begin{tabular}{|c|c|c|c|c|c|c|c|c|c|c|c|c|}
\hline $\begin{array}{l}\text { Lead Author, } \\
\text { Journal }\end{array}$ & $\begin{array}{l}\text { Patient } \\
\text { Cohort }\end{array}$ & $\begin{array}{l}\text { Healthy } \\
\text { Control }\end{array}$ & $\begin{array}{l}\text { Number of } \\
\text { Participants }\end{array}$ & $\begin{array}{l}\text { Baseline } \\
\text { Antibody } \\
\text { Measurement }\end{array}$ & Antibody Assay & Platform & Vaccine & $\begin{array}{l}\text { Seroconversion } \\
\text { Rate After 1st } \\
\text { Dose }\end{array}$ & $\begin{array}{l}\text { Seroconversion } \\
\text { Rate After 2nd } \\
\text { Dose }\end{array}$ & $\begin{array}{l}\text { Seroconversion } \\
\text { Rate of Control } \\
\text { Group }\end{array}$ & Additional Findings & Reference \\
\hline $\begin{array}{l}\text { Massarweh A, } \\
\text { JAMA Oncol }\end{array}$ & Solid Tumors & Y & $\begin{array}{l}102 \text { Patient/ } \\
78 \text { Control }\end{array}$ & $\begin{array}{l}\text { N/A } \\
\text { (No History of } \\
\text { COVID-19) }\end{array}$ & $\begin{array}{l}\text { SARS-CoV-2 lgG ॥ } \\
\text { Quant assay }\end{array}$ & $\begin{array}{l}\text { Abbott } \\
\text { (architect } \\
\text { i2000sr } \\
\text { platform) }\end{array}$ & BNT162b2 & N/A & $90 \%$ & $100 \%$ & $\begin{array}{l}\text { Lower antibody titers in patients treated } \\
\text { with chemotherapy plus immunotherapy } \\
(p=0.001)\end{array}$ & (25) \\
\hline $\begin{array}{l}\text { Herishanu Y, } \\
\text { Blood }\end{array}$ & CLL & Y & $\begin{array}{l}167 \text { Patients } \\
\text { (52 Patient } \\
\text { and } 52 \\
\text { Control for } \\
\text { Matched } \\
\text { Cohort) }\end{array}$ & $\begin{array}{l}\text { N/A } \\
\text { (No History of } \\
\text { COVID-19) }\end{array}$ & Anti-SARS-CoV-2 S & $\begin{array}{l}\text { Elecsys } \\
\text { (Analyzer: } \\
\text { Cobas E } \\
601 \text { ) }\end{array}$ & BNT162b2 & $N / A$ & $39.5 \%$ & $100 \%$ & $\begin{array}{l}\text { Lower seroconversion in patients under } \\
\text { treatment }(16 \%) \text { vs. patients with clinical } \\
\text { remission }(79.2 \%) \text { and treatment-naive } \\
\text { patients }(55.2 \%) \text { /No seroconversion in } \\
\text { patients exposed to anti-CD20 treatment } \\
\text { in last } 12 \text { months }(0 / 22)\end{array}$ & (24) \\
\hline $\begin{array}{l}\text { Palich R, Ann } \\
\text { Onc }\end{array}$ & Solid Tumors & Y & $\begin{array}{l}110 \\
\text { Patients/25 } \\
\text { Controls }\end{array}$ & $\begin{array}{l}\text { N/A } \\
\text { (Prior COVID- } \\
19 \text { infection in } \\
15 \text { patients as } \\
\text { evidenced by } \\
\text { positive anti-N } \\
\text { (gG) }\end{array}$ & $\begin{array}{l}\text { Serum } \\
\text { anti-N IgG and anti-S } \\
\lg G\end{array}$ & Abbott & BNT162b2 & $55 \%$ & N/A & $\begin{array}{l}100 \% \text { after } 1^{\text {st }} \\
\text { dose }\end{array}$ & $\begin{array}{l}\text { Lower seropositivity in }>65 \text { years (OR: } \\
3.58,95 \% \text { Cl: } 1.40-9.15, p=0.008) \text {, and } \\
\text { treatment with chemotherapy (OR: } 4.34 \text {, } \\
95 \% \text { Cl: } 1.67-11.30, p=0.003 \text { ) }\end{array}$ & (22) \\
\hline $\begin{array}{l}\text { Palich R, Ann } \\
\text { Onc }\end{array}$ & Solid Tumors & $\mathrm{Y}$ & $\begin{array}{l}223 \text { Patient/ } \\
49 \text { Control }\end{array}$ & $\begin{array}{l}\text { Negative anti- } \\
\text { SARS-CoV-2 } \\
\text { anti- } \\
\text { nucleoprotein } \\
\text { IgG }\end{array}$ & $\begin{array}{l}\text { SARS-CoV-2 } \\
\text { immunoglobulin (Ig) G/ } \\
\text { SARS-CoV-2 } \\
\text { total lg } \\
\text { electrochemiluminescent } \\
\text { immunoassay }\end{array}$ & $\begin{array}{l}\text { Abbott } \\
\text { Alinity/Roche } \\
\text { Elecsys }\end{array}$ & BNT162b2 & N/A & $94 \%$ & $100 \%$ & $\begin{array}{l}8 / 13 \text { of the seronegative patients had } \\
\text { metastatic disease and } 10 / 13 \\
\text { seronegative patients were treated with } \\
\text { chemotherapy }\end{array}$ & (39) \\
\hline $\begin{array}{l}\text { Barrière J, Ann } \\
\text { Onc }\end{array}$ & Solid Tumors & Y & $\begin{array}{l}122 \\
\text { Patients/31 } \\
\text { Controls }\end{array}$ & $\begin{array}{l}\text { Negative } \\
\text { SARS-CoV-2 } \\
\text { S }\end{array}$ & Anti-SARS-CoV-2 S & Elecsys & BNT162b2 & $47.5 \%$ & $95.2 \%$ & $100 \%$ & $\begin{array}{l}\text { Patients under active } \\
\text { CT lower seroconversion rates after first- } \\
\text { dose compared to patients without CT, } \\
\text { and patients under targeted therapy alone } \\
(42.9 \% \text { vs. } 76.5 \%, p=0.016)\end{array}$ & (27) \\
\hline $\begin{array}{l}\text { Goshen-Lago } \\
\text { T, Jama Oncol }\end{array}$ & Solid Tumors & Y & $\begin{array}{l}232 \\
\text { Patients/261 } \\
\text { Controls }\end{array}$ & $\begin{array}{l}\text { N/A } \\
\text { (No History of } \\
\text { COVID-19) }\end{array}$ & $\begin{array}{l}\text { SARS-CoV-2 anti-spike } \\
\text { (S) S1/S2 lgG assay }\end{array}$ & $\begin{array}{l}\text { Liaison }{ }^{\circledR} \\
\text { analyzer }\end{array}$ & BNT162b2 & $29 \%$ & $86 \%$ & $\begin{array}{l}84 \% \text { after } 1^{\text {st }} \\
\text { dose }\end{array}$ & $\begin{array}{l}\text { Low rates of seropositivity in patients } \\
\text { undergoing chemotherapy } \\
\text { (OR: 0.41, } 95 \% \text { Cl: } 0.17-0.98) \text { /Low rate of } \\
\text { systemic adverse events }\end{array}$ & (34) \\
\hline $\begin{array}{l}\text { Shroff RT, } \\
\text { medRxiv }\end{array}$ & Solid Tumors & $\mathrm{Y}$ & $\begin{array}{l}52 \text { Patients/ } \\
50 \text { Controls }\end{array}$ & $\begin{array}{l}\text { Neutralizing } \\
\text { antibodies } \\
\text { (WA1 isolate) }\end{array}$ & $\begin{array}{l}\text { Neutralizing antibodies } \\
\text { (WA1 isolate) }\end{array}$ & $\begin{array}{l}\text { ImmunoSpot } \\
\text { Versa }\end{array}$ & BNT162b2 & $67 \%$ & $80 \%$ & $\begin{array}{l}98 \% \text { after } 1^{\text {st }} \\
\text { dose/ } 100 \% \\
\text { after } 2^{\text {nd }} \text { dose }\end{array}$ & $\begin{array}{l}\text { Lower overall antibody and T cell } \\
\text { responses in cancer cohort compared } \\
\text { with control cohorts }\end{array}$ & (32) \\
\hline $\begin{array}{l}\text { Terpos E, J } \\
\text { Hematol Oncol }\end{array}$ & $\begin{array}{l}\text { Cancer } \\
\text { patients } \\
\text { receiving } \\
\text { checkpoint } \\
\text { inhibitors }\end{array}$ & Y & $\begin{array}{l}59 \text { Patients/ } \\
283 \text { Controls }\end{array}$ & $\begin{array}{l}\text { N/A } \\
\text { (No History of } \\
\text { COVID-19) }\end{array}$ & $\begin{array}{l}\text { Neutralizing antibodies } \\
\text { (SARS-CoV-2 NAbs } \\
\text { Detection Kit) }\end{array}$ & cPass $^{T M}$ & $\begin{array}{l}\text { BNT162b2 } \\
\text { and mRNA- } \\
1273\end{array}$ & $25 \%$ & N/A & 65.7 & $\begin{array}{l}\text { None of the patients enrolled had } \\
\text { neutropenia or lymphopenia at first } \\
\text { vaccination dose }\end{array}$ & (36) \\
\hline $\begin{array}{l}\text { Addeo A, } \\
\text { Cancer Cell }\end{array}$ & $\begin{array}{l}\text { Solid/ } \\
\text { Hematologic } \\
\text { Malignancies }\end{array}$ & $\mathrm{N}$ & 131 & $\begin{array}{l}\text { Negative anti- } \\
\text { SARS-CoV-2 } \\
\text { nucleocapsid } \\
\text { protein IgG }\end{array}$ & Anti-SARS-CoV-2 S & Elecsys & $\begin{array}{l}\text { BNT162b2 } \\
\text { and mRNA- } \\
1273\end{array}$ & $\begin{array}{l}83 \% \text { in solid } \\
\text { tumors } / 77 \% \text { in } \\
\text { hematological } \\
\text { tumors }\end{array}$ & $94 \%$ & N/A & $\begin{array}{l}\text { Lower seroconversion in hematological } \\
\text { malignancy }(77 \% \text { vs. } 98 \%) / \text { Lower } \\
\text { seroconversion in patients treated with } \\
\text { chemotherapy or immunotherapy ( } 98 \% \\
\text { vs. } 93 \% \text { and } 93 \%) / \text { No seroconversion } \\
\text { under anti-CD20 treatment (0/4) }\end{array}$ & (33) \\
\hline $\begin{array}{l}\text { Monin L, } \\
\text { Lancet Oncol }\end{array}$ & $\begin{array}{l}\text { Solid/ } \\
\text { Hematologic } \\
\text { Malignancies }\end{array}$ & Y & $\begin{array}{l}151 \\
\text { Patients/54 } \\
\text { Controls }\end{array}$ & $\begin{array}{l}\text { Negative } \\
\text { SARS-CoV-2 } \\
\text { S/Negative } \\
\text { rRT-PCR }\end{array}$ & $\begin{array}{l}\text { SARS-CoV-2 S-specific } \\
\text { IgG }\end{array}$ & Local (ELISA) & BNT162b2 & $\begin{array}{l}38 \% \text { solid tumor/ } \\
18 \% \text { hematologic } \\
\text { cancer }\end{array}$ & $\begin{array}{l}95 \% \text { solid tumor/ } \\
60 \% \text { hematologic } \\
\text { cancer }\end{array}$ & $\begin{array}{l}94 \% \text { after } 1^{\text {st }} \\
\text { dose } / 100 \% \text { after } \\
2^{\text {nd }} \text { dose }\end{array}$ & $\begin{array}{l}\text { No adverse events in more than } 50 \% \text { of } \\
\text { the patients with vaccination } / \mathrm{-cell} \\
\text { responses in } 82 \%, 71 \% \text { and } 50 \% \text { of the } \\
\text { controls, solid tumor cohort and } \\
\text { hematologic tumor cohort with first } \\
\text { vaccine dose }\end{array}$ & (28) \\
\hline $\begin{array}{l}\text { Thakkar A, } \\
\text { Cancer Cell }\end{array}$ & $\begin{array}{l}\text { Solid/ } \\
\text { Hematologic } \\
\text { Malignancies }\end{array}$ & $\mathrm{N}$ & 200 & N/A & SARS-CoV-2 IgG ॥ & $\begin{array}{l}\text { AdviseDx } \\
\text { CIMA (on } \\
\text { Abbott }\end{array}$ & $\begin{array}{l}\text { BNT162b2, } \\
\text { mRNA- }\end{array}$ & N/A & $94 \%$ & N/A & $\begin{array}{l}\text { Lower seroconversion rates in } \\
\text { hematologic malignancies ( } 85 \%) \text {, patients } \\
\text { treated with anti-CD20 therapies (70\%) }\end{array}$ & (40) \\
\hline
\end{tabular}




\begin{tabular}{|c|c|c|c|c|c|c|c|c|c|c|c|c|}
\hline $\begin{array}{l}\text { Lead Author, } \\
\text { Journal }\end{array}$ & $\begin{array}{l}\text { Patient } \\
\text { Cohort }\end{array}$ & $\begin{array}{l}\text { Healthy } \\
\text { Control }\end{array}$ & $\begin{array}{l}\text { Number of } \\
\text { Participants }\end{array}$ & $\begin{array}{c}\text { Baseline } \\
\text { Antibody } \\
\text { Measurement }\end{array}$ & Antibody Assay & Platform & Vaccine & $\begin{array}{l}\text { Seroconversion } \\
\text { Rate After 1st } \\
\text { Dose }\end{array}$ & $\begin{array}{l}\text { Seroconversion } \\
\text { Rate After 2nd } \\
\text { Dose }\end{array}$ & $\begin{array}{l}\text { Seroconversion } \\
\text { Rate of Control } \\
\quad \text { Group }\end{array}$ & Additional Findings & Reference \\
\hline & & & & $\begin{array}{l}\left({ }^{*} \text { Prior COVID- }\right. \\
19 \text { infection in } \\
18 \text { patients) }\end{array}$ & & $\begin{array}{l}\text { i2000SR } \\
\text { instrument) }\end{array}$ & $\begin{array}{l}1273 \text { and } \\
\text { Ad26 }\end{array}$ & & & & $\begin{array}{l}\text { and stem cell transplantation }(73 \%) \\
\text { compared to patients with solid tumors } \\
(98 \%) / H \text { igher seroconversion rates in } \\
\text { patients treated with immunotherapy } \\
(97 \%) \text { or hormonal therapies }(100 \%)\end{array}$ & \\
\hline $\begin{array}{l}\text { Fong D, Eur J } \\
\text { Cancer }\end{array}$ & $\begin{array}{l}\text { Solid/ } \\
\text { Hematologic } \\
\text { Malignancies }\end{array}$ & $\mathrm{N}$ & 154 & $\begin{array}{l}\text { Negative Anti- } \\
\text { SARS-CoV-2 } \\
\text { nucleocapsid } \\
\text { and spike } \\
\text { protein IgG }\end{array}$ & $\begin{array}{l}\text { SARS-CoV-2 } \\
\text { nucleocapsid and spike } \\
\text { protein IgG } \\
\text { chemiluminescent } \\
\text { immunoassay }\end{array}$ & Abbott & BNT162b2 & $61 \%$ & $85.7 \%$ & N/A & $\begin{array}{l}\text { Higher antibody titres in CoV-positive } \\
\text { patients after the first vaccine dose } \\
(p<0.001)\end{array}$ & (41) \\
\hline $\begin{array}{l}\text { Oekelen OV, } \\
\text { Cancer Cell }\end{array}$ & MM & $\mathrm{Y}$ & $\begin{array}{l}320 \\
\text { Patients/67 } \\
\text { Controls }\end{array}$ & $\begin{array}{l}\text { N/A (Prior } \\
\text { COVID-19 } \\
\text { infection in } 60 \\
\text { patients) }\end{array}$ & SARS-CoV-2 IgG test & $\begin{array}{l}\text { COVID- } \\
\text { SeroKlir } \\
\text { Kantaro }\end{array}$ & $\begin{array}{l}\text { BNT162b2 } \\
\text { and mRNA- } \\
1273\end{array}$ & $\mathrm{~N} / \mathrm{A}$ & $84.2 \%$ & $100 \%$ & $\begin{array}{l}\text { Lower seroconversion rates in patients } \\
\text { treated with anti-CD38 (HR: } 4.258 \text {, } \\
\mathrm{p}=0.005 \text { ) or } \mathrm{BCMA} \text {-targeted treatment } \\
\text { (HR: } 10.269, \mathrm{p}<0.001) / \text { Better } \\
\text { seroconversion rates in patients with } \mathrm{CR} \\
\text { (HR: } 0.389, \mathrm{p}=0.037 \text { ) }\end{array}$ & (26) \\
\hline $\begin{array}{l}\text { Bird S, Lancet } \\
\text { Haematol }\end{array}$ & MM & $\mathrm{N}$ & 93 & N/A & $\begin{array}{l}\text { Anti-SARS-CoV-2 IgG } \\
\text { and AntiSARS-CoV-2 } \\
\text { total antibody against S1 } \\
\text { spike protein }\end{array}$ & $\begin{array}{l}\text { Ortho Clinical } \\
\text { Diagnostics }\end{array}$ & $\begin{array}{l}\text { BNT162b2 } \\
\text { and } \\
\text { AZD1222 }\end{array}$ & $\begin{array}{l}56 \%(70 \% \text { total } \\
\text { antibody } \\
\text { response) }\end{array}$ & N/A & N/A & $\begin{array}{l}\text { Higher seroconversion in responding } \\
\text { patients }(p=0.0046) / \text { Lower seroconversion } \\
\text { rates in patients under treatment ( } 48 \% \text { vs. } \\
74 \%, p=0.037) / \text { Similar seroconversion } \\
\text { rates with Pfizer and AstraZeneca } \\
\text { vaccines }\end{array}$ & (42) \\
\hline $\begin{array}{l}\text { Pimpinell F, J } \\
\text { Hematol Oncol }\end{array}$ & MM/MPN & Y & $\begin{array}{l}92 \text { Patients/ } \\
36 \text { Controls }\end{array}$ & $\begin{array}{l}\text { SARS-CoV-2 } \\
\text { S1/S2 lgG test }\end{array}$ & $\begin{array}{l}\text { SARS-CoV-2 S1/S2 IgG } \\
\text { test }\end{array}$ & $\begin{array}{l}\text { Liaison }{ }^{\circledR} \\
\text { analyzer }\end{array}$ & BNT162b2 & $\begin{array}{l}21.4 \% \text { in } \\
\text { myeloma/52\% in } \\
\text { MPN }\end{array}$ & $\begin{array}{l}78.6 \% \text { in } \\
\text { myeloma/88\% in } \\
\text { MPN }\end{array}$ & $\begin{array}{l}52.8 \% \text { after } 1^{\text {st }} \\
\text { dose } / 100 \% \text { after } \\
2^{\text {nd }} \text { dose }\end{array}$ & $\begin{array}{l}\text { Lower seroconversion rates in } \\
\text { daratumumab-treated patients }(50 \% \text { vs. } \\
92.9 \%, \mathrm{p}=0.003) / L \text {. } \\
\text { adverse of systemic } \\
\text { events }\end{array}$ & (29) \\
\hline $\begin{array}{l}\text { Terpos E, } \\
\text { Blood }\end{array}$ & MM & Y & $\begin{array}{l}48 \text { Patients/ } \\
104 \text { Controls }\end{array}$ & $\begin{array}{l}\text { Neutralizing } \\
\text { Antibodies } \\
\text { Against SARS- } \\
\text { CoV-2 }\end{array}$ & $\begin{array}{l}\text { Neutralizing } \\
\text { Antibodies Against } \\
\text { SARS-CoV-2 }\end{array}$ & cPass $^{\text {TM }}$ & BNT162b2 & $25 \%$ & N/A & $\begin{array}{l}54.8 \% \text { after } 1^{\text {st }} \\
\text { dose }\end{array}$ & $\begin{array}{l}\text { All patients with clinically relevant viral } \\
\text { inhibition }(\% 4 / 4) \text { after first dose was in } \\
\text { remission without treatment }\end{array}$ & (38) \\
\hline $\begin{array}{l}\text { Lim SH, Lancet } \\
\text { Haematol }\end{array}$ & Lymphoma & Y & $\begin{array}{l}119 \\
\text { Patients/150 } \\
\text { Controls }\end{array}$ & $\begin{array}{l}\text { Negative anti- } \\
\text { SARS-CoV-2 } \\
\text { nucleocapsid } \\
\text { protein lgG }\end{array}$ & $\begin{array}{l}\text { Qualified } \\
\text { electrochemiluminescent } \\
\text { Anti-SARS-CoV-2 S } \\
\text { assay }\end{array}$ & $\begin{array}{l}\text { Meso Scale } \\
\text { Discovery }\end{array}$ & $\begin{array}{l}\text { BNT162b2 } \\
\text { and } \\
\text { AZD1222 }\end{array}$ & N/A & N/A & $100 \%$ & $\begin{array}{l}\text { Lower seroconversion rates in patients } \\
\text { who received systemic anti-lymphoma } \\
\text { therapy after the first vaccine dose ( } \mathrm{p}= \\
0.0002) \text {, after the second vaccine dose } \\
\mathrm{p}<0.001 \text { for BNT162b2 vaccine) }\end{array}$ & (44) \\
\hline $\begin{array}{l}\text { Avivi I, Br J } \\
\text { Haematol }\end{array}$ & MM & $\mathrm{Y}$ & $\begin{array}{l}171 \\
\text { Patients/64 } \\
\text { Controls }\end{array}$ & $\begin{array}{l}\text { Negative anti- } \\
\text { SARS-CoV-2 } \\
\text { nucleocapsid } \\
\text { protein lgG }\end{array}$ & Anti-SARS-CoV-2 S & Elecsys & BNT162b2 & $\mathrm{N} / \mathrm{A}$ & $78 \%$ & $98 \%$ & $\begin{array}{l}\text { Lower seroconversion rates in } \\
\text { daratumumab-treated patients ( } 69 \% \\
\text { vs. } 81 \%, p=0.08 \text { ) }\end{array}$ & (30) \\
\hline $\begin{array}{l}\text { Chowdhury O, } \\
\text { Br J Haematol }\end{array}$ & CML & $\mathrm{Y}$ & $\begin{array}{l}59 \text { Patients/ } \\
232 \text { Controls }\end{array}$ & $\begin{array}{l}\text { Negative anti- } \\
\text { SARS-CoV-2 } \\
\text { nucleocapsid } \\
\text { protein lgG }\end{array}$ & $\begin{array}{l}\text { SARS-CoV-2 lgG II } \\
\text { Quant Assay }\end{array}$ & Abbott & $\begin{array}{l}\text { BNT162b2 } \\
\text { or AZD1222 }\end{array}$ & $58 \%$ & N/A & $\begin{array}{l}97 \% \text { after } 1^{\text {st }} \\
\text { dose }\end{array}$ & $\begin{array}{l}\text { The highest seroconversion rates in } \\
\text { patients with CML }(75 \%)\end{array}$ & (37) \\
\hline $\begin{array}{l}\text { Roeker LE, } \\
\text { Leukemia }\end{array}$ & $\mathrm{CLL}$ & $\mathrm{N}$ & 44 & N/A & $\begin{array}{l}\text { SARS-CoV-2 S1/S2 lgG } \\
\text { assay }\end{array}$ & Liaison ${ }^{\circledR}$ & $\begin{array}{l}\text { BNT162b2 } \\
\text { and mRNA- } \\
1273\end{array}$ & $\mathrm{~N} / \mathrm{A}$ & $52 \%$ & N/A & $\begin{array}{l}\text { Lower seropositivity in }>70 \text { years (OR: } 12 \text {, } \\
\text { 95\% Cl: } 2.9-50.5, p=0.001 \text { ), and prior- } \\
\text { CLL directed therapy (OR: } 56.7,95 \% \mathrm{Cl} \text { : } \\
6.2-518, p<0.001 \text { ) }\end{array}$ & (45) \\
\hline $\begin{array}{l}\text { Agha M, } \\
\text { medRxiv }\end{array}$ & $\begin{array}{l}\text { Hematologic } \\
\text { Malignancies }\end{array}$ & $\mathrm{N}$ & 67 & $\begin{array}{l}\text { N/A } \\
\text { (No History of } \\
\text { COVID-19) }\end{array}$ & $\begin{array}{l}\text { Semi-quantitative SARS- } \\
\text { CoV-2 IgG against the } \\
\text { Spike protein receptor- } \\
\text { binding domain }\end{array}$ & $\begin{array}{l}\text { Beckman } \\
\text { Coulter } \\
\text { SARS-CoV-2 } \\
\text { platform }\end{array}$ & $\begin{array}{l}\text { BNT162b2 } \\
\text { and mRNA- } \\
1273\end{array}$ & $\mathrm{~N} / \mathrm{A}$ & $53.7 \%$ & $\mathrm{~N} / \mathrm{A}$ & $\begin{array}{l}\text { Lower seroconversion in CLL patients } \\
\text { compared to patients with other } \\
\text { hematological malignancies }(23.1 \% \text { vs } \\
61.1 \%, p=0.01)\end{array}$ & (46) \\
\hline $\begin{array}{l}\text { Diefenbach C, } \\
\text { medRxiv }\end{array}$ & $\begin{array}{l}\text { CLL, HL and } \\
\mathrm{NHL}\end{array}$ & Y & $\begin{array}{l}53 \text { Patients/ } \\
5 \text { Controls }\end{array}$ & $\mathrm{N} / \mathrm{A}$ & $\begin{array}{l}\text { Multiplex bead-binding } \\
\text { IgG spike and receptor } \\
\text { binding domain assay for } \\
\text { SARS-CoV2 }\end{array}$ & $\begin{array}{l}\text { Yeti ZE5 Cell } \\
\text { Analyzer }\end{array}$ & $\begin{array}{l}\text { BNT162b2 } \\
\text { and mRNA- } \\
1273\end{array}$ & $47.1 \%$ & $\mathrm{~N} / \mathrm{A}$ & $100 \%$ & $\begin{array}{l}\text { Lower seroconversion rates in patients } \\
\text { treated with anti-CD20 ( } p<0.001) \text { and } \\
\text { BTK inhibitors }(p=0.003) \text { /No effect of }\end{array}$ & (47) \\
\hline
\end{tabular}




\begin{tabular}{|c|c|c|c|c|c|c|c|c|c|c|c|c|}
\hline $\begin{array}{l}\text { Lead Author, } \\
\text { Journal }\end{array}$ & $\begin{array}{l}\text { Patient } \\
\text { Cohort }\end{array}$ & $\begin{array}{l}\text { Healthy } \\
\text { Control }\end{array}$ & $\begin{array}{l}\text { Number of } \\
\text { Participants }\end{array}$ & $\begin{array}{l}\text { Baseline } \\
\text { Antibody } \\
\text { Measurement }\end{array}$ & Antibody Assay & Platform & Vaccine & $\begin{array}{l}\text { Seroconversion } \\
\text { Rate After 1st } \\
\text { Dose }\end{array}$ & $\begin{array}{l}\text { Seroconversion } \\
\text { Rate After 2nd } \\
\text { Dose }\end{array}$ & $\begin{array}{l}\text { Seroconversion } \\
\text { Rate of Control } \\
\quad \text { Group }\end{array}$ & Additional Findings & Reference \\
\hline & & & & & & & & & & & $\begin{array}{l}\text { additional boost on antibody titers in most } \\
\text { patients }(94 \%)\end{array}$ & \\
\hline $\begin{array}{l}\text { Gavriatopoulou } \\
\text { M, Clin Exp } \\
\text { Med. }\end{array}$ & $\begin{array}{l}\text { WM, CLL } \\
\text { and NHL }\end{array}$ & Y & $\begin{array}{l}58 \text { Patients/ } \\
213 \text { Controls }\end{array}$ & $\begin{array}{l}\text { N/A } \\
\text { (No History of } \\
\text { COVID-19) }\end{array}$ & Neutralizing antibodies & cPass $^{\mathrm{TM}}$ & $\begin{array}{l}\text { BNT162b2 } \\
\text { and } \\
\text { AZD1222 }\end{array}$ & $14 \%$ & N/A & $\% 54$ & $\begin{array}{l}\text { Lower response rates }(<30 \%) \text { in patients } \\
\text { under active treatment }\end{array}$ & (35) \\
\hline $\begin{array}{l}\text { Tzarfati KH, Am } \\
\text { J Hematol }\end{array}$ & $\begin{array}{l}\text { Hematologic } \\
\text { Malignancies }\end{array}$ & Y & $\begin{array}{l}315 \\
\text { Patients/108 } \\
\text { Controls }\end{array}$ & $\begin{array}{l}\text { N/A } \\
\text { (No History of } \\
\text { COVID-19) }\end{array}$ & $\begin{array}{l}\text { SARS-CoV-2 S1/S2 lgG } \\
\text { test }\end{array}$ & Liaison ${ }^{\circledR}$ & BNT162b2 & $\mathrm{N} / \mathrm{A}$ & $75 \%$ & $99 \%$ & $\begin{array}{l}\text { Older age }(p<0.001) \text {, higher lactate } \\
\text { dehydrogenase }(p=0.02) \text {, and number of } \\
\text { treatment lines }(p<0.001) \text { was correlated } \\
\text { with lower seropositivity } \\
\text { Absolute lymphocyte count ( } p 0.001) \text {, total } \\
\text { globulin level ( }(p=0.002) \text {, and time from last } \\
\text { treatment to vaccination }(p<0.001) \\
\text { correlated with higher seropositivity } \\
\text { likelihood and antibody titers }\end{array}$ & (31) \\
\hline $\begin{array}{l}\text { Harrington P, } \\
\text { Leukemia }\end{array}$ & CML & N & 16 & $\begin{array}{l}\text { Negative anti- } \\
\text { SARS-CoV-2 } \\
\text { anti- } \\
\text { nucleoprotein } \\
\text { IgG }\end{array}$ & $\begin{array}{l}\text { SARS-CoV-2 Anti-S IgG } \\
\text { ELISA }\end{array}$ & Local & BNT162b2 & $81.25 \%$ & N/A & N/A & $\begin{array}{l}\text { Higher post-vaccine anti-S IgG EC50 and } \\
\text { neutralising antibody ID50 titres in } \\
\text { myelofibrosis patients }(n=9) \text { compared to } \\
\text { patients with other MPN subtypes ( } p= \\
0.012)\end{array}$ & (48) \\
\hline $\begin{array}{l}\text { Harrington } P \text {, } \\
\text { Br J Haematol }\end{array}$ & CML & N & 16 & $\begin{array}{l}\text { Negative Anti- } \\
\text { SARS-CoV-2 } \\
\text { nucleocapsid } \\
\text { and spike } \\
\text { protein IgG }\end{array}$ & $\begin{array}{l}\text { SARS-CoV-2 Anti-S IgG } \\
\text { ELISA }\end{array}$ & Local & BNT162b2 & $87.5 \%$ & N/A & N/A & $\begin{array}{l}\text { No statistical difference seen between } \\
\text { diffrent TKIs in neutralising antibody titres } \\
(p=0.68)\end{array}$ & (49) \\
\hline $\begin{array}{l}\text { Re D, Leuk } \\
\text { Lymphoma }\end{array}$ & $\begin{array}{l}\text { Hematologic } \\
\text { Malignancies }\end{array}$ & $\mathrm{N}$ & 102 & $\begin{array}{l}\text { N/A } \\
\text { (No History of } \\
\text { COVID-19) }\end{array}$ & $\begin{array}{l}\text { Commercially avaible kit } \\
\text { detecting SARS-CoV-2 } \\
\text { anti-spike (S) }\end{array}$ & N/A & $\begin{array}{l}\text { BNT162b2 } \\
\text { and mRNA- } \\
1273\end{array}$ & N/A & $62.7 \%$ & N/A & $\begin{array}{l}\text { Lower seroconversion rates after the first } \\
\text { vaccine dose in patients who received } \\
\text { anti-CD20 treatment beyond the last } 12 \\
\text { months ( }(p<0.0001)\end{array}$ & (43) \\
\hline
\end{tabular}

ALC, Absolute lymphocyte count; BCMA, B cell maturation antigen; BTK, Bruton tyrosine kinase, CML, Chronic myeloid leukemia; CLL, Chronic lymphocytic leukemia; COVID-19, Coronavirus disease 2019; HL, Hodgkin lymphoma; CT, Chemotherapy; MM, Multiple myeloma; MPN, Myeloproliferative neoplasms; N/A, Not available; NHL, Non-Hodgkin lymphoma; RBD, receptor binding domain; SARS-CoV-2, Severe Acute Respiratory Syndrome Coronavirus-2; WM. Waldenstrom macroglobulinemia. 


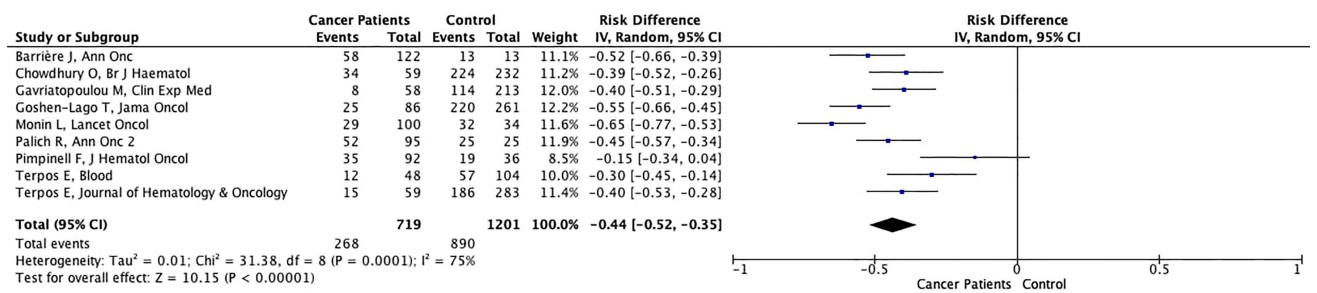

FIGURE 3 | Forest plot illustrating the risk differences of seroconversion rates between cancer patients and healthy controls with first dose of vaccination.

AZD1222 vaccines, the seroconversion rates were significantly lower in cancer patients (RD: $-0.40 \%, 95 \%$ CI: $-0.47 \%,-0.33 \%$, $\mathrm{p}<0.001$ ) (Supplement). The separate data on the seroconversion rates with mRNA and AZD1222 vaccines was only available in one study. The seroconversion rates were similar for AZD1222 (59.5\%) and BNT162b2 (54.5\%) vaccines in this study after the first dose of vaccination (37).

\section{Seroconversion Rates After Second Vaccination}

In contrast to low seroconversion rates after the first dose of vaccination, patients with solid tumors who received their complete vaccination had seroconversion rates greater than $90 \%$. Likewise, patients with hematologic malignancies had over $75 \%$ seroconversion rates in all but one study (24). Additionally, anti-CD20 treatments in lymphoma patients and anti-CD38 treatments in multiple myeloma patients were associated with low seroconversion rates in $5(24,33,40,43$, 47 ) and 3 studies $(26,29,30)$, respectively. By comparison, the seroconversion rates almost $100 \%$ in the control arms with complete vaccination in all reported studies (538/540, 99.6\%).

The possibility of achieving seroconversion was $19 \%$ lower in cancer patients (78.3\%) compared to controls (99.6\%) (RD: $-0.19 \%, 95 \%$ CI: $-0.28 \%,-0.10 \%, \mathrm{p}<0.001)$, in the pooled data of ten studies with available seroconversion rates after complete vaccination (Figure 4). The antibody titers were lower in cancer patients than controls in most studies including control arms (Table 2). In contrast, Goshen-Lago (34) and Addeo et al. (33) reported similar neutralizing anti-SARS-CoV-2 antibody titers in patients with active cancer and patients whose cancer is in remission, respectively. The difference in seroconversion rates was more pronounced for patients with hematologic malignancies $(733 / 1010,72.6 \%)$ (RD: $-0.25 \%$, 95\% CI: $-0.27 \%$, $-0.22 \%, \mathrm{p}<0.001$ ) (Figure 5A) than patients with solid tumors $(401 / 438,91.6 \%)$

(RD: $-0.09 \%, 95 \%$ CI: $-0.13 \%,-0.04 \%, \mathrm{p}<0.003$ ) (Figure 5B). Additionally, six studies (five involving only patients with hematologic malignancies) reported specific outcomes for patients in remission. In the pooled analysis of 5 studies with control arms, the cancer patients in remission had significantly lower seroconversion rates than healthy controls albeit with a smaller risk difference (RD: $-0.10 \%, 95 \%$ CI: $-0.14 \%,-0.06 \%$, $\mathrm{p}<0.001$ ) (Figure 5C). Significant heterogeneity was present in all analyses other than analyses in the solid tumor subgroup $\left(\mathrm{I}^{2}=43 \%\right.$ ) (Figures 4, 5A-C). Nine of the ten studies included patients vaccinated with the BNT162b2 vaccine, while the study by Oekelen et al. (26)included patients vaccinated with the BNT162b2 or mRNA-1273 vaccine. Due to use of mRNA vaccines in all of the studies, no stratification could be done according to vaccine type.

\section{DISCUSSION}

To the best of our knowledge, this was the first meta-analysis on the antibody responses to COVID-19 vaccination in cancer patients. In the pooled analyses of the studies, cancer patients had significantly lower seroconversion rates with one or two doses of vaccination. The seroconversion rates were especially lower in patients with hematologic malignancies, while patients

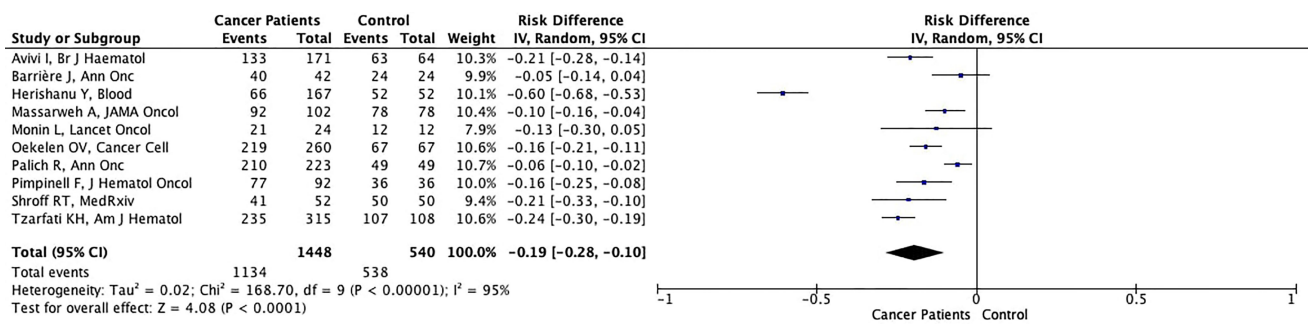

FIGURE 4 | Forest plot illustrating the risk differences of seroconversion rates between cancer patients and healthy controls after second dose of vaccination. 


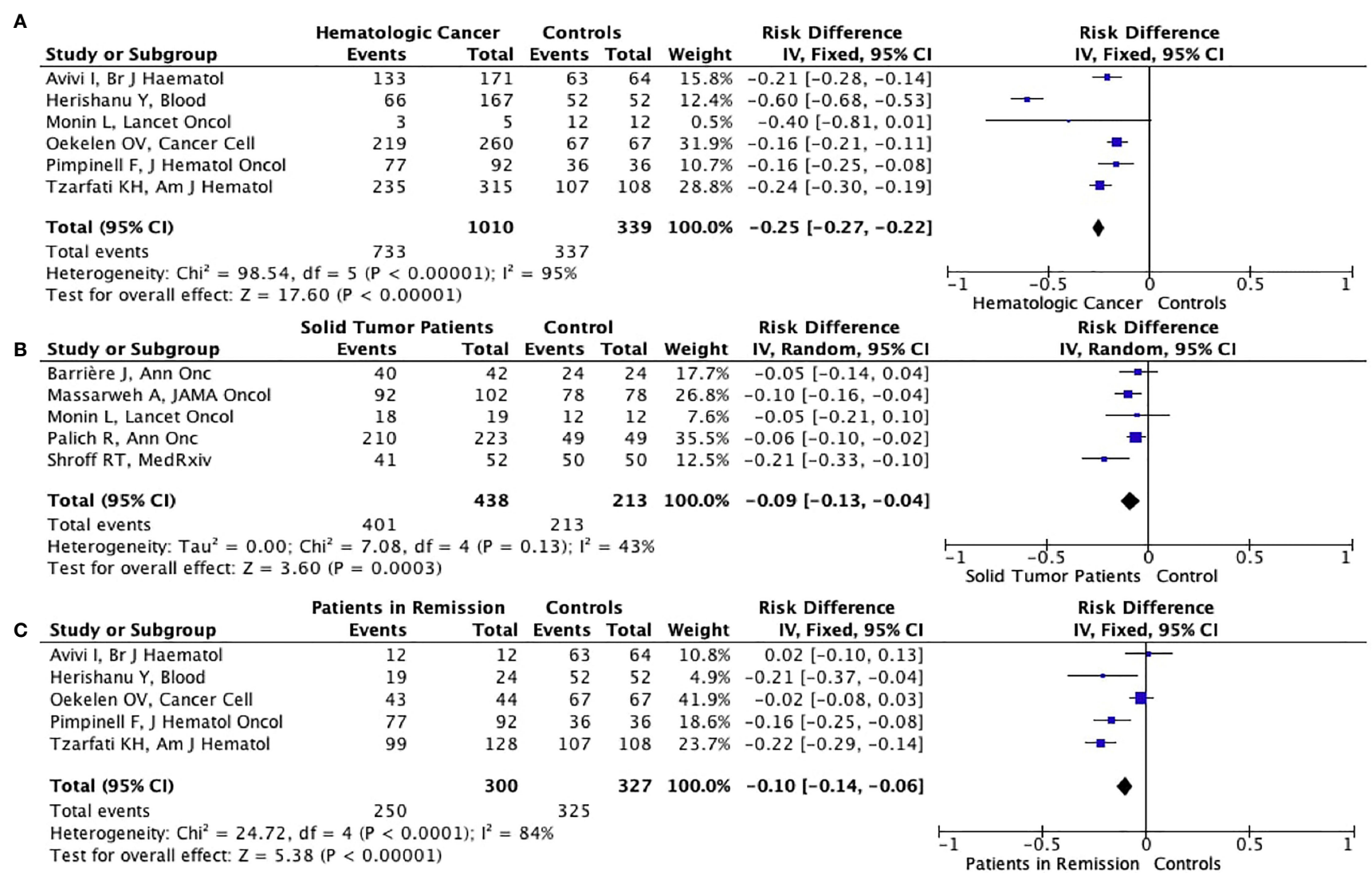

FIGURE 5ABC | Forest plot illustrating the risk differences of seroconversion rates between patients with hematologic malignancies (A), solid tumors (B) or patients in remission $\mathbf{( C )}$ and healthy controls after second dose of vaccination.

with solid tumors and patients in remission had slightly reduced antibody responses to vaccination.

Vaccination against SARS-CoV-2 is vital for patients with cancer. However, T-cell immunity is severely impaired in most cancer patients which could reduce the immune responses to vaccines (50). The first clue of this problem was evident in the study by Solodky et al. reporting significantly lower seroconversion rates in cancer patients after SARS-CoV-2 infection (30\% in cancer patients $v s .71 \%$ in health care workers, $\mathrm{p}=0.04)(51)$. However, the sample size was very small $(n=24)(51)$. Marra et al. challenged this finding in a larger cohort $(n=166)$ and reported similar seropositivity between cancer patients (80.5\%) and health care workers (87.9\%) after COVID-19 infection ( $\mathrm{p}=0.39)$ (52). Later, Takkar and colleagues demonstrated a high seroconversion rate (92\%) in the 261 patients with cancer after COVID-19 disease, although significantly lower seroconversion rates in patients with hematological malignancies (82\%) and patients who received antiCD20 treatment (59\%) were concerning (53).

Cancer patients were among the prioritized groups of persons for COVID-19 vaccination (18). However, the data on the efficacy of vaccines were limited in cancer patients due to the exclusion of these patients from clinical trials. This issue made studies from real-world evidence settings imperative and led to a continuous effort in that direction. The earliest studies evaluated the seroconversion rates after the single vaccine dose and focused on the hematological cancers as a susceptible group for low seroconversion rates. Single-dose mass vaccination, generally with a prolonged delay for the second dose, was proposed to provide a broader vaccine coverage due to the limited vaccine supply (15). Initial reports reported over $70 \%$ protection from symptomatic COVID-19 disease with a single dose vaccine in the general population $(54,55)$ and this observation created the foundation of extended interval vaccination in England to vaccinate a larger part of the population with at least one vaccine dose. However, this strategy seems risky and not sustainable for cancer patients considering their already significantly lower seroconversion rates with first vaccine dose $(37.3 \%$ in cancer patients vs. $74.1 \%$ in controls, Figure 3). Antibody titers were also significantly lower with a single vaccine dose in seroconverted patients $(22,29,33)$, necessitating the application of a second dose vaccine in a time interval recommended in clinical trials.

Although the seroconversion rate for cancer patients was increased after the second dose of the vaccine, the rate was still significantly lower than the controls. Patients with solid tumors had over $90 \%$ seroconversion rates, while the patients with hematologic malignancies had significantly lower seroconversion rates 
(Table 2). The lower seroconversion rates were especially prominent in patients with lymphoid malignancies (Table 2). Additionally, patients treated anti-B cell antibodies targeting CD20 or CD38 antigens as part of their standard of care had significantly lower antibody responses after COVID-19 vaccination $(26,33)$. The negative effect of anti-CD20 therapy appeared to be long-lasting, as evidenced by lack of seroconversion in 22 chronic lymphocytic leukemia patients who were treated with anti-CD20 antibodies within the last 12 months (24). We think that these patients should be prioritized for novel approaches for COVID-19 like anti-SARS-COV-2 antibody studies (56) and third dose vaccinations (57).

An early report in 30 solid organ transplant recipients with negative or low antibody levels after two vaccination doses, an additional vaccine boost increased antibody titers in all patients with low antibody response (6/6) and created seroconversion in the 6 of 24 seronegative patients. $80 \%$ of the study population were received boosts with a different vaccine in the study (58). An anecdotal report by Hill et al. also supported the possible benefit of an additional boost with a heterologous vaccine providing seroconversion in a seronegative lymphoma patient (59). Recently, a phase II study with CoronaVac vaccine in healthy adults reported significantly increased antibody titers with a third dose boost which applied 6-8 months after the second dose in patients became seronegative (60). If further research supports these observations, the seronegative patients with cancer could benefit from a three-dose vaccination schedule similar to strategies with influenza and hepatitis $B$ vaccinations $(61,62)$. In contrast to those observations, a small study on 18 seronegative CLL, NHL and myeloma patients with two doses of BNT162b2 vaccination demonstrated no seronconversion with a third dose (57). A large phase I study is currently evaluating the benefit of a three-dose vaccination in 1000 patients with cancer (NCT04936997) and hopefully could aid to determine the best strategy in seronegative cancer patients. While the oncology community is eagerly awaiting the results of three-dose vaccination studies, the Centers for Disease Control and Prevention (CDC) recommended a third-dose Pfizer/BioNTech (BNT162b2) and Moderna (mRNA-1273) vaccine booster in solid organ transplantation patients or who have a similar level of immunosuppression based on the two studies in transplantation patients demonstrating more than a $30 \%$ increase in seroconversion rates with a third-dose boost $(63,64)$. This immunosuppression definition includes cancer patients under active treatment or patients who had stem cell transplantation in the last two years and these patients should have a third-dose booster until further data is available (65). Several other countries including Italy and Turkey also recommended a third-dose booster in older patients and patients with comorbidities creating immunosuppression. However, data on the booster dose efficacy in immunosuppressed patients is not available for other vaccines including inactive whole virus vaccines and viral vector vaccines.

There are still significant knowledge gaps and unanswered questions. The seroconversion is often used as a surrogate laboratory marker of adaptive immunity against vaccination in immunocompromised cohorts $(29,66)$. However, the available studies have yet to report any meaningful correlation between measured anti-SARS-Cov-2 antibody titers and T-cell immunity against COVID-19 in cancer patients following vaccination. Tcells are the main actors of the fight against COVID-19 and the creation of the long-lasting immune memory against COVID-19 (67) and could be a better reflector of the immunity against COVID-19. A recent report with the BBIBP-CorV vaccine reported no significant correlation between the serum IgG antibody titers and interferon-gamma concentrations in the peripheral blood mononuclear cells $(\mathrm{p}=0.11)$ (68) suggesting antibody measurements could be imprecise to detect SARSCoV-2 specific adaptive immunity. The imprecision of seroconversion as a COVID-19 vaccine efficacy was further supported by the work of Tzarfati and colleagues. The authors reported no COVID-19 cases in 315 patients with hematologic malignancies vaccinated with two doses of BNT162b2 vaccine, albeit with a relatively low seroconversion rate $(75 \%)$ in the cohort pointing out the limitation of seroconversion rate as the sole denominator of immunity (31). The evaluation of T-cell immunity with vaccination is being addressed in the SOAP-02 study (28) and could be especially important in patients with low or negative antibody responses to vaccination (69). In addition to the one-dimensional nature of antibody measurements as a denominator of vaccine efficacy, the SARS-CoV-2 antibody assays have previously been reported to suffer from moderate concordance and variable sensitivities. These inherent limitations have emerged as an important challenge in accurately diagnosing the SARS-CoV-2 infection during the early phases of pandemic (70-72). Several new strategies including the combined use of ELISA and virus neutralization tests have been proposed to improve the diagnosis of COVID-19 by increasing the sensitivity of detection for SARS-CoV-2 (73). The diagnostic challenges have resolved with with the rapid development of assays with significantly improved sensitivity and specificity (74). While several studies have previously evaluated the vaccine seroconversion rates based on antibody assays with lower sensitivities $(29,31)$ or antibody assays without an FDA authorization developed for research purposes (32), a consistent trend across studies and the use of Elecsys and Abbott spike IgG assays ( $>95 \%$ sensitivity and specificity for both) (Table 2), have decreased the possibility of confounding problems due to antibody assay performance during the evaluation of seroconversion rates with COVID-19 vaccination.

Furthermore, B-cell immunity against COVID-19 is hampered by emergence of variants of concern, such as B.1.1.7 (alpha strain from UK), B1.351 (beta strain from South Africa), B.1.617.2 (delta strain from India) and P.1 (gamma strain from Brazil) characterized by mutant spike proteins, that may not be effectively neutralized by low titers of anti-SARS-CoV-2 spike protein antibodies induced by available COVID-19 vaccine platforms using the ancestral strain of SARS-CoV-2. A recent study from the United Kingdom reported modestly decreased vaccine efficacy against delta variant, especially with a single-dose vaccination (75). The authors including 316 participants from the clinically extremely vulnerable group, including cancer patients. However, a separate dataset was not 
available for cancer patients (75). The results of COVIVAC-ID (NCT04844489) and EREVA (NCT04952766) studies are eagerly anticipated to delineate the vaccine efficacy against variants of concern in cancer patients.

Another knowledge gap pertains to the effects of different anticancer treatments on antibody responses to COVID-19 vaccination, especially immunotherapy and chemotherapy. Previous studies have demonstrated that cancer patients treated with immune checkpoint inhibitors (ICIs) or precision medicines (e.g. tyrosine kinase inhibitors) who subsequently develop COVID19 , can enjoy survival outcomes that are similar to the survival outcomes of the general population with COVID-19 $(3,76)$. It's hypothesized that cancer patients treated with ICI or precision medicines have significant $\mathrm{T}$-cell immunity against viral infections $(76,77)$. The retained T-cell immunity could also orchestrate efficient responses to vaccination (78), similar to the robust antibody responses to COVID-19 vaccination in myeloma patients with treated with immunomodulatory agents (79). However, in part due to a focus on hematological cancers and the lack of separate studies for seroconversion rates, the published information regarding the seroconversion rates for cancer patients treated with ICI or precision medicines is very limited and the data is unequivocal. Addeo et al. reported similar seroconversion rates (93\% in both) in ICI- versus chemotherapy treated patients. But the median antibody titers $(1.116 v s .611 \mathrm{U} / \mathrm{mL})$ and seroconversion rates after the first vaccine dose (85 vs. 69\%) were significantly higher in ICI-treated patients compared to patients treated with cytotoxic chemotherapy. Additionally, 21 of the 22 patients treated with anti-HER2, anti-VEGF, RANKL inhibitors or kinase inhibitors had reportedly seroconversion after two vaccine doses (33). Similarly, Thakkar et al. reported $97 \%$ and $100 \%$ seroconversion rates in patients treated with ICI and hormonal therapy, respectively (40). Singer et al. reported higher seroconversion rates in ICI-treated patients compared to patients treated with chemotherapy, targeted therapy or radiotherapy. Additionally, the seroconversion rates were higher with the ICIchemotherapy combinations than patients treated with chemotherapy only, supporting a possible benefit of ICIs in immune response against vaccination (80). In contrast, Massarweh et al. pointed out a possible adverse synergistic effects of combined ICI + chemotherapy or biotherapy on COVID-19 antibody responses and reported significantly lower median antibody titers in patients treated with combinations of ICI and chemotherapy or biotherapy than patients treated with chemotherapy alone (25). Similarly, Terpos et al. reported significantly lower seroconversion rates after first vaccination dose in 59 ICI-treated patients compared to healthy controls (25 vs. $65.7 \%, \mathrm{p}<0001$ ) (36). These unequivocal findings emphasize the need for additional studies focusing on these patients. Similarly, whether antibody responses were impaired in patients treated with radiation therapy remains to be deciphered.

An important point is the paucity of data on the optimal vaccination schedule in cancer patients with COVID-19 history. While these patients are vaccinated with schedules similar to general population as seen in the reported studies (Table 2), Reynolds et al. reported robust $\mathrm{T}$ and $\mathrm{B}$-cell responses against
B.1.1.7 variant with a single boost of mRNA vaccine in 25 patients with COVID-19 history (81). Similarly, Fong et al. reported significantly higher seroconversion rates in cancer patients with COVID-19 history $(\mathrm{n}=89)$ compared to patients without COVID-19 history $(\mathrm{n}=154)(91 \%$ vs. 61\%) (41). Whether a single dose vaccination strategy could be suitable in patients with COVID-19 history should investigated in larger cohorts. Further, it is unknown whether available vaccines differ in protecting cancer patients from symptomatic or severe COVID-19. The available studies were mostly conducted with mRNA vaccines, and Addeo et al. reported similar seroconversion rates with two different mRNA vaccines (33), while Lim et al. reported similar antibody responses to BNT162b2 and ChAdOx1 vaccines in lymphoma patients (44). While the mRNA and adenovirus vectors attach to different tolllike receptors (TLR7 and TLR9, respectively), after the TLR attachment both vaccines cause the type I interferon secretion and the activation of the CD4-positive T-cells. This mechanism of action suggests both vaccines could have a similar efficacy from a biologic standpoint (82). However, several parts of the World, including China, Russia, and India, use different vaccines. Reports from different parts of the World will be critically important and could direct the optimal vaccination planning for cancer patients in the future. Studies with the different vaccines from these countries, and separate reporting for seroconversion rates with different vaccines is vital for the future studies and vaccination planning in cancer patients.

In conclusion, patients with cancer had significant seroconversion rates with a two-dose vaccination schedule, while seroconversion rates were significantly lower in patients with hematological malignancies and patients under active treatment. Given the life-saving nature of anti-cancer treatments, further research focusing on these patients is urgently needed.

\section{DATA AVAILABILITY STATEMENT}

The original contributions presented in the study are included in the article/Supplementary Material. Further inquiries can be directed to the corresponding author.

\section{AUTHOR CONTRIBUTIONS}

DG and FMU have planned the work. DG, TS, SK and FMU participated in data collection. All authors have made significant and substantive contributions to the reporting of the work, drafting of the manuscript, review and revisions of the final draft. All coauthors qualify the criteria for authorship according to Vancouver protocol.

\section{SUPPLEMENTARY MATERIAL}

The Supplementary Material for this article can be found online at: https://www.frontiersin.org/articles/10.3389/fonc.2021. 759108/full\#supplementary-material 


\section{REFERENCES}

1. World Health Organization. COVID-19 Weekly Epidemiological Update, edition 45. World Health Organization (2021).

2. Tian Y, Qiu X, Wang C, Zhao J, Jiang X, Niu W, et al. Cancer Associates With Risk and Severe Events of COVID-19: A Systematic Review and Meta-Analysis. Int J Cancer (2021) 148(2):363-74. doi: 10.1002/ ijc. 33213

3. Lee LY, Cazier J-B, Angelis V, Arnold R, Bisht V, Campton NA, et al. COVID19 Mortality in Patients With Cancer on Chemotherapy or Other Anticancer Treatments: A Prospective Cohort Study. Lancet (London England) (2020) 395(10241):1919-26. doi: 10.1016/S0140-6736(20)31173-9

4. Lee LYW, Cazier J-B, Starkey T, Briggs SEW, Arnold R, Bisht V, et al. COVID-19 Prevalence and Mortality in Patients With Cancer and the Effect of Primary Tumour Subtype and Patient Demographics: A Prospective Cohort Study. Lancet Oncol (2020) 21(10):1309-16. doi: 10.1016/S14702045(20)30442-3

5. Mato AR, Roeker LE, Lamanna N, Allan JN, Leslie L, Pagel JM, et al. Outcomes of COVID-19 in Patients With CLL: A Multicenter International Experience. Blood (2020) 136(10):1134-43. doi: 10.1182/ blood.2020006965

6. Sette A, Crotty S. Adaptive Immunity to SARS-CoV-2 and COVID-19. Cell (2021) 184(4):861-80. doi: 10.1016/j.cell.2021.01.007

7. Derosa L, Melenotte C, Griscelli F, Gachot B, Marabelle A, Kroemer G, et al. The Immuno-Oncological Challenge of COVID-19. Nat Cancer (2020) 1 (10):946-64. doi: 10.1038/s43018-020-00122-3

8. Mansi L, Spehner L, Daguindau E, Bouiller K, Almotlak H, Stein U, et al. Study of the SARS-CoV-2-Specific Immune T-Cell Responses in COVID-19Positive Cancer Patients. Eur J Cancer (2021) 150:1-9. doi: 10.1016/ j.ejca.2021.03.033

9. Taborska P, Strizova Z, Stakheev D, Sojka L, Bartunkova J, Smrz D. CD4(+) T Cells of Prostate Cancer Patients Have Decreased Immune Responses to Antigens Derived From SARS-CoV-2 Spike Glycoprotein. Front Immunol (2021) 12:629102. doi: 10.3389/fimmu.2021.629102

10. Bange EM, Han NA, Wileyto P, Kim JY, Gouma S, Robinson J, et al. CD8+ T Cells Contribute to Survival in Patients With COVID-19 and Hematologic Cancer. Nat Med (2021) 27(7):1280-9. doi: 10.1038/s41591-021-01386-7

11. Guven DC, Aktas BY, Aksun MS, Ucgul E, Sahin TK, Yildirim HC, et al. COVID-19 Pandemic: Changes in Cancer Admissions. BMJ Support Palliat Care (2020) doi: 10.1136/bmjspcare-2020-002468

12. Madhi SA, Baillie V, Cutland CL, Voysey M, Koen AL, Fairlie L, et al. Efficacy of the ChAdOx1 Ncov-19 Covid-19 Vaccine Against the B.1.351 Variant. N Engl J Med (2021) 384(20):1885-98. doi: 10.1056/NEJMoa2102214

13. Baden LR, El Sahly HM, Essink B, Kotloff K, Frey S, Novak R, et al. Efficacy and Safety of the mRNA-1273 SARS-CoV-2 Vaccine. N Engl J Med (2020) 384 (5):403-16. doi: 10.1056/NEJMoa2035389

14. Polack FP, Thomas SJ, Kitchin N, Absalon J, Gurtman A, Lockhart S, et al. Safety and Efficacy of the BNT162b2 mRNA Covid-19 Vaccine. N Engl J Med (2020) 383(27):2603-15. doi: 10.1056/NEJMoa2034577

15. Mathieu E, Ritchie H, Ortiz-Ospina E, Roser M, Hasell J, Appel C, et al. A Global Database of COVID-19 Vaccinations. Nat Hum Behav (2021) 5 (7):947-53. doi: 10.1038/s41562-021-01122-8

16. Ritchie H, Ortiz-Ospina E, Beltekian D, Mathieu E, Hasell J, Macdonald B, et al. Coronavirus Pandemic (COVID-19). World Data (2020).

17. Garassino MC, Vyas M, De Vries E, Kanesvaran R, Giuliani R, Peters S. The ESMO Call to Action on COVID-19 Vaccinations and Patients With Cancer: Vaccinate. Monitor. Educate. Ann Oncol (2021) 32(5):579-81. doi: 10.1016/ j.annonc.2021.01.068

18. Ribas A, Sengupta R, Locke T, Zaidi SK, Campbell KM, Carethers JM, et al. Priority COVID-19 Vaccination for Patients With Cancer While Vaccine Supply is Limited. Cancer Discov (2021) 11(2):233-6. doi: 10.1158/21598290.CD-20-1817

19. Desai A, Gainor JF, Hegde A, Schram AM, Curigliano G, Pal S, et al. COVID19 Vaccine Guidance for Patients With Cancer Participating in Oncology Clinical Trials. Nat Rev Clin Oncol (2021) 18(5):313-9. doi: 10.1038/s41571021-00487-z

20. Mandal A, Singh P, Samaddar A, Singh D, Verma M, Rakesh A, et al. Vaccination of Cancer Patients Against COVID-19: Towards the End of a
Dilemma. Med Oncol (Northwood London England) (2021) 38(8):92. doi: 10.1007/s12032-021-01540-8

21. Loulergue P, Alexandre J, Iurisci I, Grabar S, Medioni J, Ropert S, et al. Low Immunogenicity of Seasonal Trivalent Influenza Vaccine Among Patients Receiving Docetaxel for a Solid Tumour: Results of a Prospective Pilot Study. Br J Cancer (2011) 104(11):1670-4. doi: 10.1038/bjc.2011.142

22. Palich R, Veyri M, Marot S, Vozy A, Gligorov J, Maingon P, et al. Weak Immunogenicity After a Single Dose of SARS-CoV-2 mRNA Vaccine in Treated Cancer Patients. Ann Oncol (2021) 32(8):1051-3. doi: 10.1016/ j.annonc.2021.04.020

23. Moher D, Liberati A, Tetzlaff J, Altman DG. Preferred Reporting Items for Systematic Reviews and Meta-Analyses: The PRISMA Statement. BMJ (2009) 339:b2535. doi: 10.1371/journal.pmed.1000097

24. Herishanu Y, Avivi I, Aharon A, Shefer G, Levi S, Bronstein Y, et al. Efficacy of the BNT162b2 mRNA COVID-19 Vaccine in Patients With Chronic Lymphocytic Leukemia. Blood (2021) 137(23):3165-73. doi: 10.1182/ blood.2021011568

25. Massarweh A, Eliakim-Raz N, Stemmer A, Levy-Barda A, Yust-Katz S, Zer A, et al. Evaluation of Seropositivity Following BNT162b2 Messenger RNA Vaccination for SARS-CoV-2 in Patients Undergoing Treatment for Cancer. JAMA Oncol (2021) 7(8):1133-40. doi: 10.1001/jamaoncol.2021.2155

26. Van Oekelen O, Gleason CR, Agte S, Srivastava K, Beach KF, Aleman A, et al. Highly Variable SARS-CoV-2 Spike Antibody Responses to Two Doses of COVID-19 RNA Vaccination in Patients With Multiple Myeloma. Cancer Cell (2021) 39(8):1028-30. doi: 10.1016/j.ccell.2021.06.014

27. Barrière J, Chamorey E, Adjtoutah Z, Castelnau O, Mahamat A, Marco S, et al. Impaired Immunogenicity of BNT162b2 Anti-SARS-CoV-2 Vaccine in Patients Treated for Solid Tumors. Ann Oncol (2021) 32(8):1053-5. doi: 10.1016/j.annonc.2021.04.019

28. Monin L, Laing AG, Muñoz-Ruiz M, McKenzie DR, del Molino del Barrio I, Alaguthurai T, et al. Safety and Immunogenicity of One Versus Two Doses of the COVID-19 Vaccine BNT162b2 for Patients With Cancer: Interim Analysis of a Prospective Observational Study. Lancet Oncol (2021) 22 (6):765-78. doi: 10.1016/S1470-2045(21)00213-8

29. Pimpinelli F, Marchesi F, Piaggio G, Giannarelli D, Papa E, Falcucci P, et al. Fifth-Week Immunogenicity and Safety of Anti-SARS-CoV-2 BNT162b2 Vaccine in Patients With Multiple Myeloma and Myeloproliferative Malignancies on Active Treatment: Preliminary Data From a Single Institution. J Hematol Oncol (2021) 14(1):81. doi: 10.1186/s13045-02101090-6

30. Avivi I, Balaban R, Shragai T, Sheffer G, Morales M, Aharon A, et al. Humoral Response Rate and Predictors of Response to BNT162b2 mRNA COVID19 Vaccine in Patients With Multiple Myeloma. Br J Haematol (2021) 195 (2):186-93. doi: 10.1111/bjh.17608

31. Herzog Tzarfati K, Gutwein O, Apel A, Rahimi-Levene N, Sadovnik M, Harel L, et al. BNT162b2 COVID-19 Vaccine is Significantly Less Effective in Patients With Hematologic Malignancies. Am J Hematol (2021) 96 (10):1195-203. doi: 10.1002/ajh.26284

32. Shroff RT, Chalasani P, Wei R, Pennington D, Quirk G, Schoenle MV, et al. Immune Responses to COVID-19 mRNA Vaccines in Patients With Solid Tumors on Active, Immunosuppressive Cancer Therapy. MedRxiv: Preprint Server Health Sci (2021). doi: 10.1101/2021.05.13.21257129

33. Addeo A, Shah PK, Bordry N, Hudson RD, Albracht B, Di Marco M, et al. Immunogenicity of SARS-CoV-2 Messenger RNA Vaccines in Patients With Cancer. Cancer Cell (2021) 39(8):1091-98.e2. doi: 10.1016/j.ccell.2021.06.009

34. Goshen-Lago T, Waldhorn I, Holland R, Szwarcwort-Cohen M, ReinerBenaim A, Shachor-Meyouhas Y, et al. Serologic Status and Toxic Effects of the SARS-CoV-2 BNT162b2 Vaccine in Patients Undergoing Treatment for Cancer. JAMA Oncol (2021) 7(10):1507-13. doi: 10.1001/jamaoncol. 2021.2675

35. Gavriatopoulou M, Terpos E, Kastritis E, Briasoulis A, Gumeni S, NtanasisStathopoulos I, et al. Low Neutralizing Antibody Responses in WM, CLL and NHL Patients After the First Dose of the BNT162b2 and AZD1222 Vaccine. Clin Exp Med (2021), 1-5. doi: 10.1007/s10238-021-00746-4

36. Terpos E, Zagouri F, Liontos M, Sklirou AD, Koutsoukos K, Markellos C, et al. Low Titers of SARS-CoV-2 Neutralizing Antibodies After First Vaccination Dose in Cancer Patients Receiving Checkpoint Inhibitors. J Hematol Oncol (2021) 14(1):86. doi: 10.1186/s13045-021-01099-x 
37. Chowdhury O, Bruguier H, Mallett G, Sousos N, Crozier K, Allman C, et al. Impaired Antibody Response to COVID-19 Vaccination in Patients With Chronic Myeloid Neoplasms. Br J Haematol (2021) 194(6):1010-5. doi: 10.1111/bjh.17644

38. Terpos E, Trougakos IP, Gavriatopoulou M, Papassotiriou I, Sklirou AD, Ntanasis-Stathopoulos I, et al. Low Neutralizing Antibody Responses Against SARS-CoV-2 in Older Patients With Myeloma After the First BNT162b2 Vaccine Dose. Blood (2021) 137(26):3674-6. doi: 10.1182/ blood.2021011904

39. Palich R, Veyri M, Vozy A, Marot S, Gligorov J, Benderra MA, et al. High Seroconversion Rate But Low Antibody Titers After Two Injections of BNT162b2 (Pfizer-BioNTech) Vaccine in Patients Treated With Chemotherapy for Solid Cancers. Ann Oncol: Off J Eur Soc Med Oncol (2021) 32(10):1294-5. doi: 10.1016/j.annonc.2021.06.018

40. Thakkar A, Gonzalez-Lugo JD, Goradia N, Gali R, Shapiro LC, Pradhan K, et al. Seroconversion Rates Following COVID-19 Vaccination Among Patients With Cancer. Cancer Cell (2021) 39(8):1081-90.e2. doi: 10.1016/ j.ccell.2021.06.002

41. Fong D, Mair MJ, Mitterer M. High Levels of Anti-SARS-CoV-2 IgG Antibodies in Previously Infected Patients With Cancer After a Single Dose of BNT 162b2 Vaccine. Eur J Cancer (2021) 154:4-6. doi: 10.1016/ j.ejca.2021.05.036

42. Bird S, Panopoulou A, Shea RL, Tsui M, Saso R, Sud A, et al. Response to First Vaccination Against SARS-CoV-2 in Patients With Multiple Myeloma. Lancet Haematol (2021) 8(6):e389-92. doi: 10.1016/S2352-3026(21)00110-1

43. Re D, Barrière J, Chamorey E, Delforge M, Gastaud L, Petit E, et al. Low Rate of Seroconversion After mRNA Anti-SARS-CoV-2 Vaccination in Patients With Hematological Malignancies. Leuk Lymphoma (2021) 1-3. doi: 10.1080/ 10428194.2021.1957877

44. Lim SH, Campbell N, Johnson M, Joseph-Pietras D, Collins GP, O’Callaghan A, et al. Antibody Responses After SARS-CoV-2 Vaccination in Patients With Lymphoma. Lancet Haematol (2021) 8(8):e542-4. doi: 10.1016/S2352-3026 (21)00199-X

45. Roeker LE, Knorr DA, Thompson MC, Nivar M, Lebowitz S, Peters N, et al. COVID-19 Vaccine Efficacy in Patients With Chronic Lymphocytic Leukemia. Leukemia (2021) 35(9):2703-5. doi: 10.1038/s41375-021-01270-w

46. Agha M, Blake M, Chilleo C, Wells A, Haidar G. Suboptimal Response to COVID-19 mRNA Vaccines in Hematologic Malignancies Patients. medRxiv (2021). doi: 10.1101/2021.04.06.21254949

47. Diefenbach C, Caro J, Koide A, Grossbard M, Goldberg JD, Raphael B, et al. Impaired Humoral Immunity to SARS-CoV-2 Vaccination in Non-Hodgkin Lymphoma and CLL Patients. MedRxiv: Preprint Server Health Sci (2021). doi: 10.1101/2021.06.02.21257804

48. Harrington P, de Lavallade H, Doores KJ, O’Reilly A, Seow J, Graham C, et al. Single Dose of BNT162b2 mRNA Vaccine Against SARS-CoV-2 Induces High Frequency of Neutralising Antibody and Polyfunctional T-Cell Responses in Patients With Myeloproliferative Neoplasms. Leukemia (2021). doi: 10.1038/s41375-021-01300-7

49. Harrington P, Doores KJ, Radia D, O’Reilly A, Lam HPJ, Seow J, et al. Single Dose of BNT162b2 mRNA Vaccine Against Severe Acute Respiratory Syndrome Coronavirus-2 (SARS-CoV-2) Induces Neutralising Antibody and Polyfunctional T-Cell Responses in Patients With Chronic Myeloid Leukaemia. Br J Haematol (2021) 194(6):999-1006. doi: 10.1111/bjh.17568

50. Zhang Z, Liu S, Zhang B, Qiao L, Zhang Y, Zhang Y. T Cell Dysfunction and Exhaustion in Cancer. Front Cell Dev Biol (2020) 8(17). doi: 10.3389/ fcell.2020.00017

51. Solodky ML, Galvez C, Russias B, Detourbet P, N'Guyen-Bonin V, Herr AL, et al. Lower Detection Rates of SARS-COV2 Antibodies in Cancer Patients Versus Health Care Workers After Symptomatic COVID-19. Ann Oncol (2020) 31(8):1087-8. doi: 10.1016/j.annonc.2020.04.475

52. Marra A, Generali D, Zagami P, Cervoni V, Gandini S, Venturini S, et al. Seroconversion in Patients With Cancer and Oncology Health Care Workers Infected by SARS-CoV-2. Ann Oncol (2021) 32(1):113-9. doi: 10.1016/ j.annonc.2020.10.473

53. Thakkar A, Pradhan K, Jindal S, Cui Z, Rockwell B, Shah AP, et al. Patterns of Seroconversion for SARS-CoV-2 IgG in Patients With Malignant Disease and Association With Anticancer Therapy. Nat Cancer (2021) 2(4):392-9. doi: 10.1038/s43018-021-00191-y
54. Pilishvili T, Fleming-Dutra KE, Farrar JL, Gierke R, Mohr NM, Talan DA, et al. Interim Estimates of Vaccine Effectiveness of Pfizer-BioNTech and Moderna COVID-19 Vaccines Among Health Care Personnel-33 US Sites, January-March 2021. Morb Mortal Wkly Rep (2021) 70(20):753. doi: 10.15585/mmwr.mm7020e2

55. Sadoff J, Gray G, Vandebosch A, Cárdenas V, Shukarev G, Grinsztejn B, et al. Safety and Efficacy of Single-Dose Ad26.Cov2.S Vaccine Against Covid-19. N Engl J Med (2021) 384(23):2187-201. doi: 10.1056/ NEJMoa2101544

56. O'Brien MP, Forleo-Neto E, Musser BJ, Isa F, Chan K-C, Sarkar N, et al. Subcutaneous REGEN-COV Antibody Combination to Prevent Covid-19. N Engl J Med (2021) 385(13):1184-95. doi: 10.1056/NEJMoa2109682

57. Re D, Seitz-Polski B, Carles M, Brglez V, Graça D, Benzaken S, et al. Humoral and Cellular Responses After a Third Dose of BNT162b2 Vaccine in Patients Treated for Lymphoid Malignancies. medRxiv (2021). doi: 10.1101/ 2021.07.18.21260669

58. Werbel WA, Boyarsky BJ, Ou MT, Massie AB, Tobian AAR, Garonzik-Wang JM, et al. Safety and Immunogenicity of a Third Dose of SARS-CoV-2 Vaccine in Solid Organ Transplant Recipients: A Case Series. Ann Intern Med (2021) 174(9):1330-2. doi: 10.1001/jama.2021.4385

59. Hill JA, Ujjani CS, Greninger AL, Shadman M, Gopal AK. Immunogenicity of a Heterologous COVID-19 Vaccine After Failed Vaccination in a Lymphoma Patient. Cancer Cell (2021) 39(8):1037-8. doi: 10.1016/j.ccell.2021.06.015

60. Pan H, Wu Q, Zeng G, Yang J, Jiang D, Deng X, et al. Immunogenicity and Safety of a Third Dose, and Immune Persistence of CoronaVac Vaccine in Healthy Adults Aged 18-59 Years: Interim Results From a Double-Blind, Randomized, Placebo-Controlled Phase 2 Clinical Trial. medRxiv (2021). doi: 10.1101/2021.07.23.21261026

61. Rubin LG, Levin MJ, Ljungman P, Davies EG, Avery R, Tomblyn M, et al. 2013 IDSA Clinical Practice Guideline for Vaccination of the Immunocompromised Host. Clin Infect Dis (2014) 58(3):e44-100. doi: $10.1093 / \mathrm{cid} / \mathrm{cit} 684$

62. Rieger CT, Liss B, Mellinghoff S, Buchheidt D, Cornely OA, Egerer G, et al. Anti-Infective Vaccination Strategies in Patients With Hematologic Malignancies or Solid Tumors-Guideline of the Infectious Diseases Working Party (AGIHO) of the German Society for Hematology and Medical Oncology (DGHO). Ann Oncol: Off J Eur Soc Med Oncol (2018) 29 (6):1354-65. doi: 10.1093/annonc/mdy117

63. Kamar N, Abravanel F, Marion O, Couat C, Izopet J, Del Bello A. Three Doses of an mRNA Covid-19 Vaccine in Solid-Organ Transplant Recipients. N Engl J Med (2021) 385(7):661-2. doi: 10.1056/NEJMc2108861

64. Hall VG, Ferreira VH, Ku T, Ierullo M, Majchrzak-Kita B, Chaparro C, et al. Randomized Trial of a Third Dose of mRNA-1273 Vaccine in Transplant Recipients. N Engl J Med (2021) 385(13):1244-6. doi: 10.1056/NEJMc2111462

65. In Brief: Third Dose of mRNA-Based COVID-19 Vaccines for Immunocompromised Persons. Med Lett Drugs Ther (2021) 63(1633):145-6.

66. Jin P, Li J, Pan H, Wu Y, Zhu F. Immunological Surrogate Endpoints of COVID-2019 Vaccines: The Evidence We Have Versus the Evidence We Need. Signal Transduct Target Ther (2021) 6(1):48. doi: 10.1038/s41392-02100481-y

67. Le Bert N, Tan AT, Kunasegaran K, Tham CYL, Hafezi M, Chia A, et al SARS-CoV-2-Specific T Cell Immunity in Cases of COVID-19 and SARS, and Uninfected Controls. Nature (2020) 584(7821):457-62. doi: 10.1038/s41586020-2550-Z

68. Deng Y, Li Y, Yang R, Tan W. SARS-CoV-2-Specific T Cell Immunity to Structural Proteins in Inactivated COVID-19 Vaccine Recipients. Cell Mol Immunol (2021) 18(8):2040-1. doi: 10.1038/s41423-021-00730-8

69. Sahin U, Muik A, Vogler I, Derhovanessian E, Kranz LM, Vormehr M, et al. BNT162b2 Vaccine Induces Neutralizing Antibodies and Poly-Specific T Cells in Humans. Nature (2021) 595(7868):572-7. doi: 10.1038/s41586021-03653-6

70. Guevara-Hoyer K, Fuentes-Antrás J, de la Fuente-Muñoz E, Rodríguez de la Peña A, Viñuela M, Cabello-Clotet N, et al. Serological Tests in the Detection of SARS-CoV-2 Antibodies. Diagnostics (2021) 11(4):678. doi: 10.3390/ diagnostics 11040678

71. Falzone L, Gattuso G, Tsatsakis A, Spandidos DA, Libra M, Falzone L, et al. Current and Innovative Methods for the Diagnosis of COVID-19 Infection (Review). Int J Mol Med (2021) 47(6):100. doi: 10.3892/ijmm.2021.4933 
72. Theel ES, Slev P, Wheeler S, Couturier MR, Wong SJ, Kadkhoda K. The Role of Antibody Testing for SARS-CoV-2: Is There One? J Clin Microbiol (2020) 58(8):e00797-20. doi: 10.1128/JCM.00797-20

73. James J, Rhodes S, Ross CS, Skinner P, Smith SP, Shipley R, et al. Comparison of Serological Assays for the Detection of SARS-CoV-2 Antibodies. Viruses (2021) 13(4):713. doi: 10.3390/v13040713

74. Coste AT, Jaton K, Papadimitriou-Olivgeris M, Greub G, Croxatto A. Comparison of SARS-CoV-2 Serological Tests With Different Antigen Targets. J Clin Virol (2021) 134:104690. doi: 10.1016/j.jcv.2020.104690

75. Lopez Bernal J, Andrews N, Gower C, Gallagher E, Simmons R, Thelwall S, et al. Effectiveness of Covid-19 Vaccines Against the B.1.617.2 (Delta) Variant. N Engl J Med (2021) 385(7):585-94. doi: 10.1056/NEJMoa 2108891

76. Vivarelli S, Falzone L, Grillo CM, Scandurra G, Torino F, Libra M. Cancer Management During COVID-19 Pandemic: Is Immune Checkpoint Inhibitors-Based Immunotherapy Harmful or Beneficial? Cancers (2020) 12 (8):2237. doi: 10.3390/cancers 12082237

77. Yekedüz E, Dursun B, Aydın GÇ, Yazgan SC, Öztürk HH, Azap A, et al. Clinical Course of COVID-19 Infection in Elderly Patient With Melanoma on Nivolumab. J Oncol Pharm Pract (2020) 26(5):1289-94. doi: 10.1177/ 1078155220924084

78. Vivarelli S, Falzone L, Torino F, Scandurra G, Russo G, Bordonaro R, et al. Immune-Checkpoint Inhibitors From Cancer to COVID-19: A Promising Avenue for the Treatment of Patients With COVID-19 (Review). Int J Oncol (2021) 58(2):145-57. doi: 10.3892/ijo.2020.5159

79. Terpos E, Gavriatopoulou M, Ntanasis-Stathopoulos I, Briasoulis A, Gumeni S, Malandrakis P, et al. The Neutralizing Antibody Response Post COVID-19 Vaccination in Patients With Myeloma is Highly Dependent on the Type of Anti-Myeloma Treatment. Blood Cancer J (2021) 11(8):138. doi: 10.1038/ s41408-021-00530-3
80. Singer J, Le N-S, Mattes D, Klamminger V, Hackner K, Kolinsky N, et al. Evaluation of Antibody Responses to COVID-19 Vaccines Among Solid Tumor and Hematologic Patients. Cancers (Basel) (2021) 13(17):4312. doi: $10.3390 /$ cancers 13174312

81. Reynolds CJ, Pade C, Gibbons JM, Butler DK, Otter AD, Menacho K, et al. Prior SARS-CoV-2 Infection Rescues B and T Cell Responses to Variants After First Vaccine Dose. Science (2021) 372(6549):1418. doi: 10.1126/science.abh1282

82. Teijaro JR, Farber DL. COVID-19 Vaccines: Modes of Immune Activation and Future Challenges. Nat Rev Immunol (2021) 21(4):195-7. doi: 10.1038/ s41577-021-00526-x

Conflict of Interest: FMU was employed by Ares Pharmaceuticals, LLC and was a consultant for Aptevo Therapeutics and for Reven Pharmaceuticals.

The remaining authors declare that the research was conducted in the absence of any commercial or financial relationships that could be construed as a potential conflict of interest.

Publisher's Note: All claims expressed in this article are solely those of the authors and do not necessarily represent those of their affiliated organizations, or those of the publisher, the editors and the reviewers. Any product that may be evaluated in this article, or claim that may be made by its manufacturer, is not guaranteed or endorsed by the publisher.

Copyright (C) 2021 Guven, Sahin, Kilickap and Uckun. This is an open-access article distributed under the terms of the Creative Commons Attribution License (CC BY).

The use, distribution or reproduction in other forums is permitted, provided the original author(s) and the copyright owner(s) are credited and that the original publication in this journal is cited, in accordance with accepted academic practice. No use, distribution or reproduction is permitted which does not comply with these terms. 